رخداد زئوليتهاى ير كننده حفرهها و شكستگى ها در مجموعه آتشفشانى شمال غرب

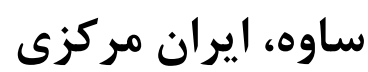

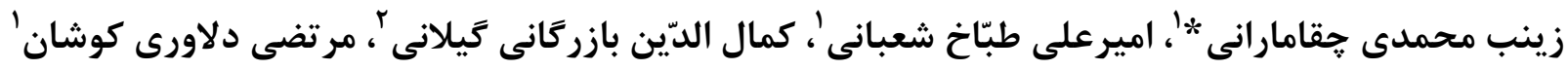

1 - I - دانشكده علوم زمين، دانشكاه خوارزمى، تهران

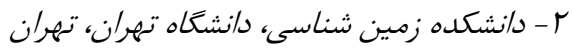

(دريافت مقالة:

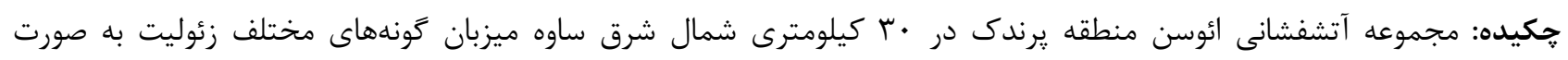

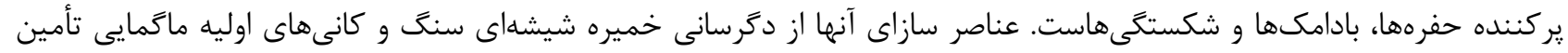

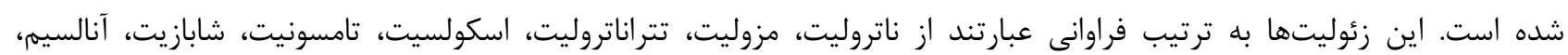

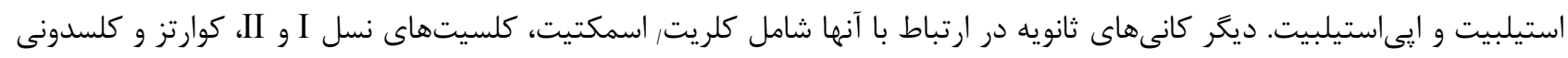
هستند. تشكيل زئوليتها در بازالتهاى منطقه مورد بررسى با نسبت Si/Al كم با زئوليتهاى سديمدار شروع و به تدريج با افزايش

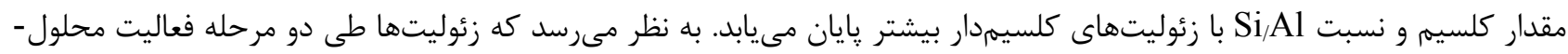

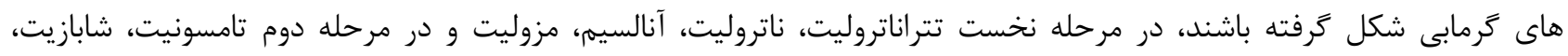

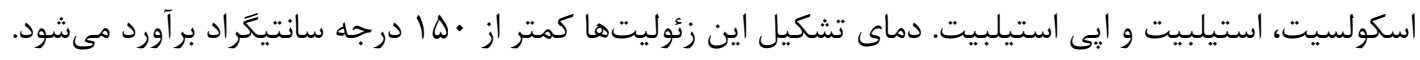

وازههاى كليدى: بازالت؛ زئوليتها؛ دكرسانى كرمابي؛ ائوسن؛ برندك؛ ساوه.

ساختار آنها سه بعدى بوده و از خاروجهى هاى مشخص تشكيل

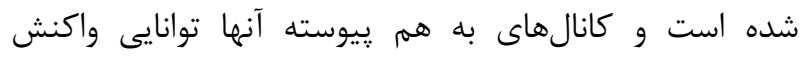

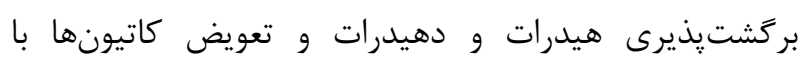

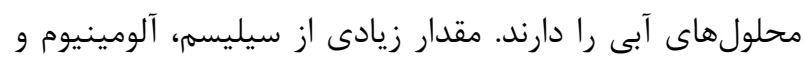

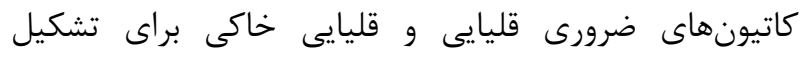

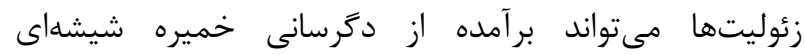

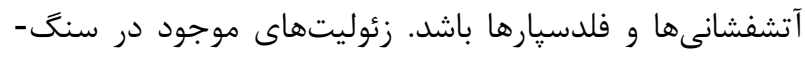

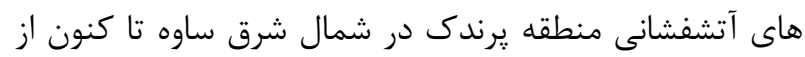

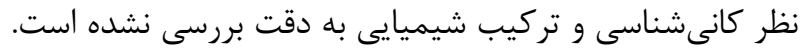

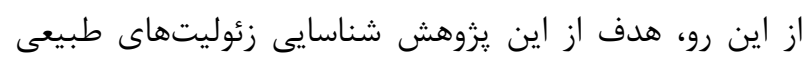

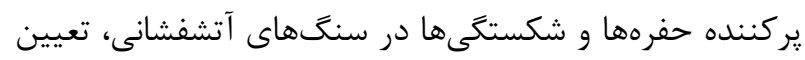

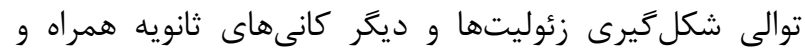

خاستكاه آنهاست.
مقدمه زئوليتها در محيطهاى مختلف زمينشناسى تشكيل مىشائرندا

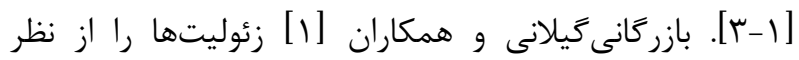

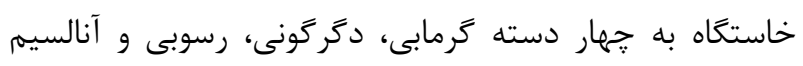

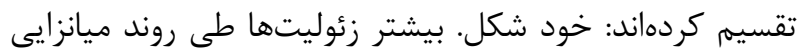

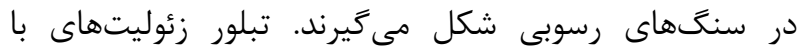

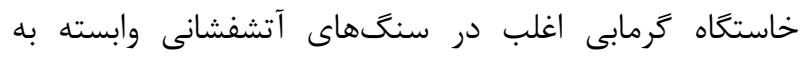

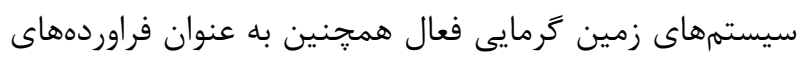
دكرسانى در راستاى صفحهاى گسلها، شكستكى ها و حفرهانها

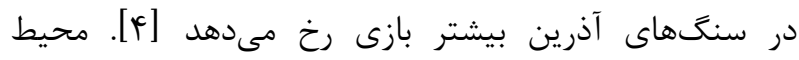

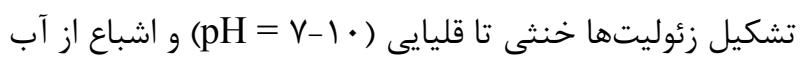

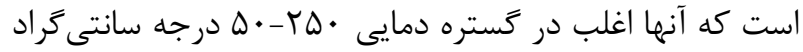

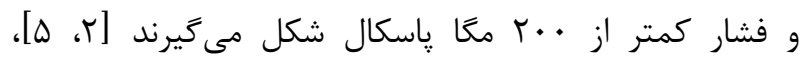


يورفيرى و حفرهدار است كه كاهى به علت وجود اكسيدهاى

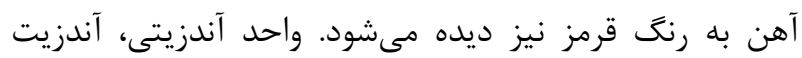

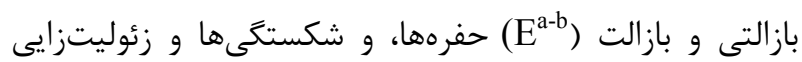

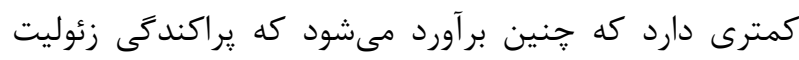

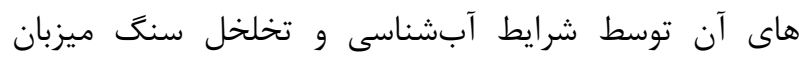
كنترل شده باشد [س، عائ.

\section{روشهاى بررسى}

بررسىهاى صحرايى جهت شناسايى زئوليتها و سنگ ميزبان

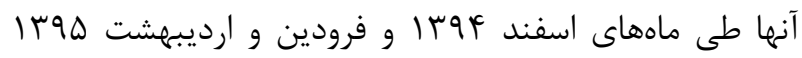

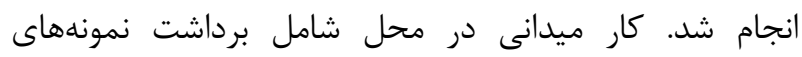

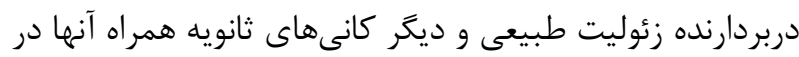

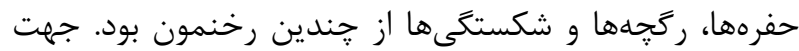

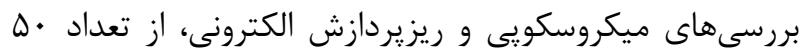

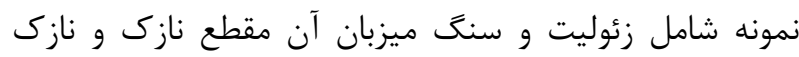

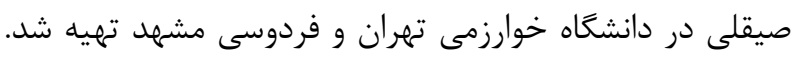

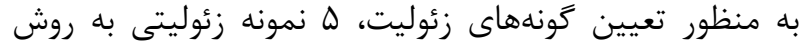

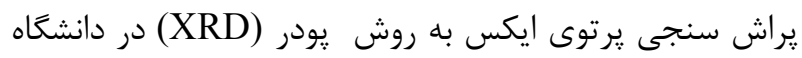

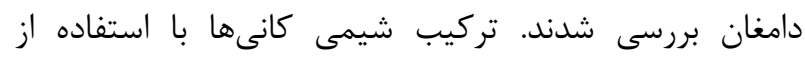

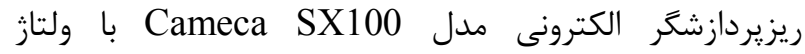

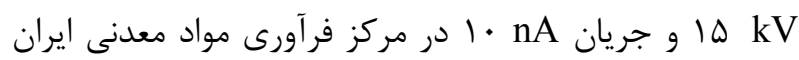
براى ب نمونه مقطع نازك صيقلى تعيين شد
زمين شناسى منطقه

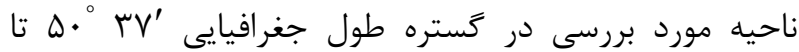
غ FD'

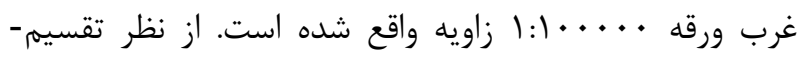
بندى زمينشناسى ساختارى، مجموعه سنگ رئهاى آتشفشانى

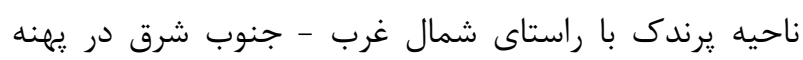

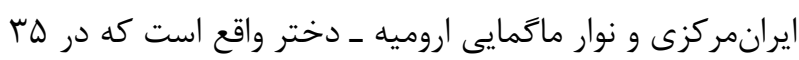

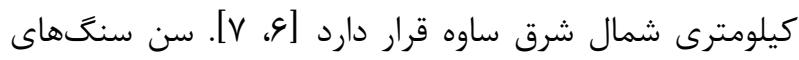

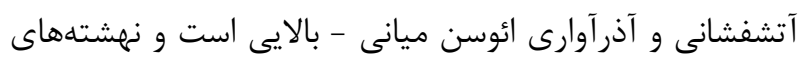

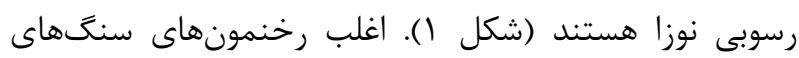

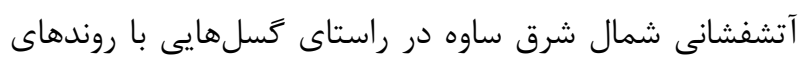

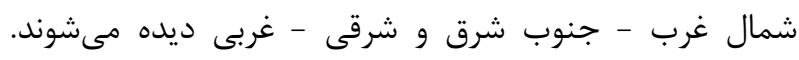
قسمتهاى شرق و جنوب منطقه مورد بررسى توسط رسوب-

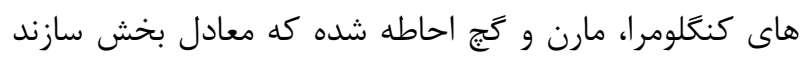
سرخ بالايى است.

\section{بر بى هاى صحرايى}

Eر منطقه يرندى غنى ترين واحد از نظر زئوليتزايى واحد

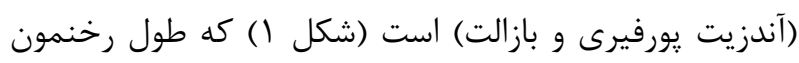

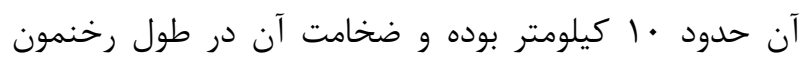

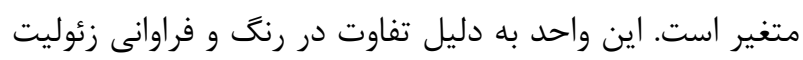

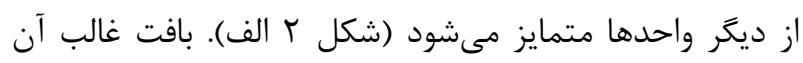

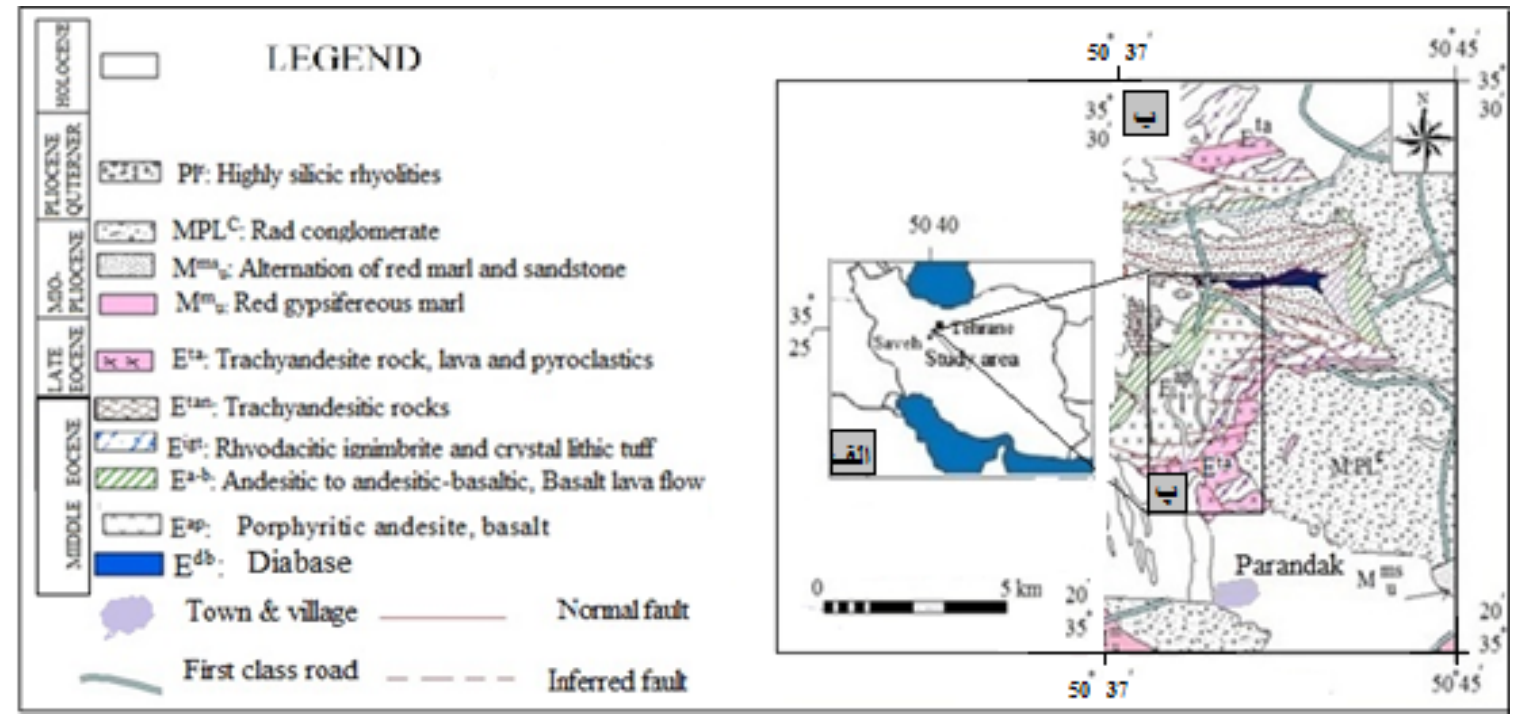

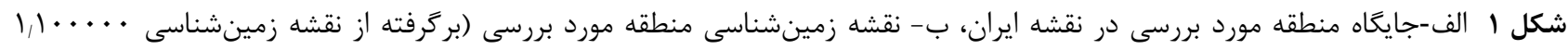

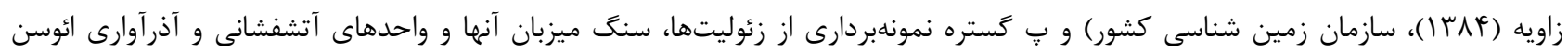
ميانى و بالايى. 

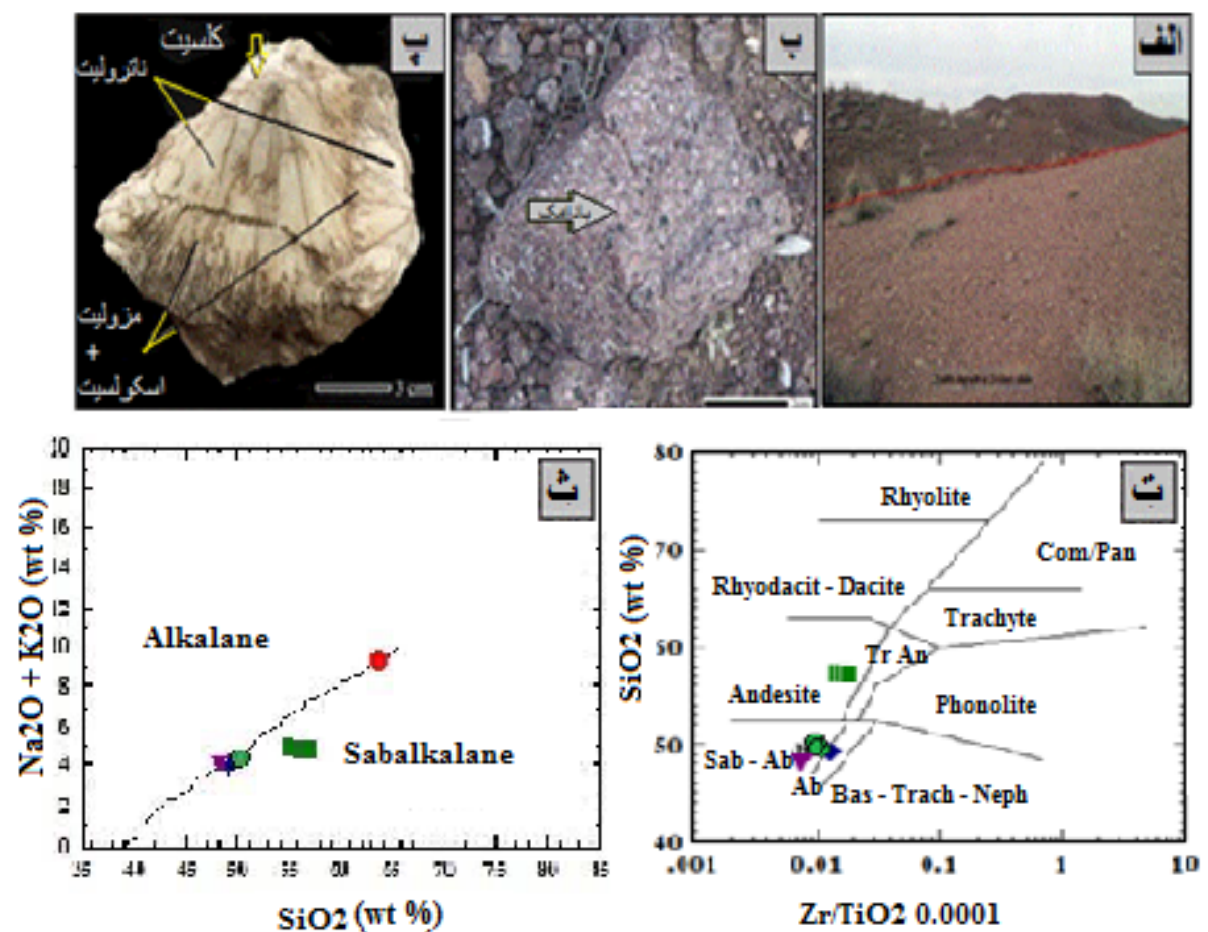

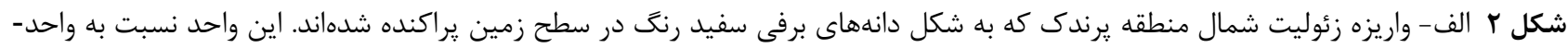

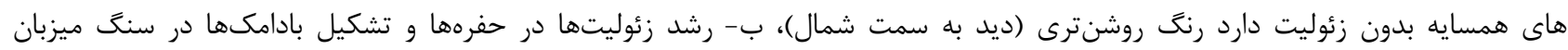

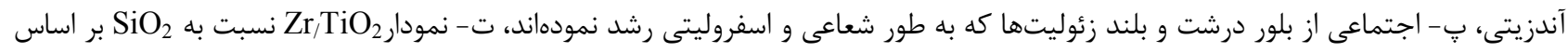

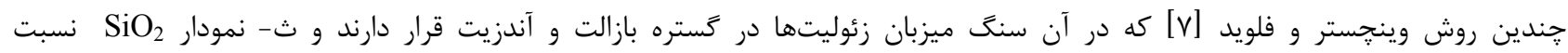

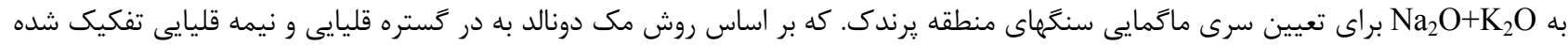

قرار دارند (شكل r ت). با توجه به شكل r ث، سرى ماتمايى

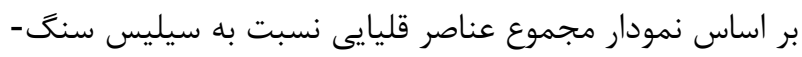

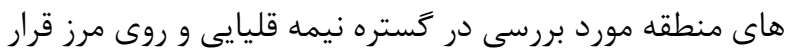

دارند [9]

\section{سنغَنَارى و زمينشيمى زئوليتها}

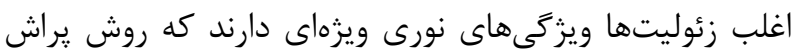

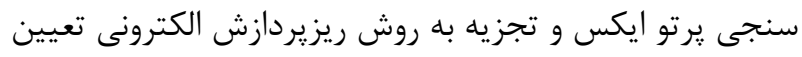

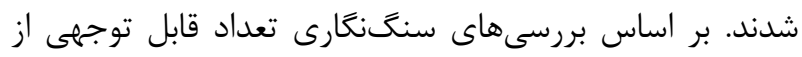

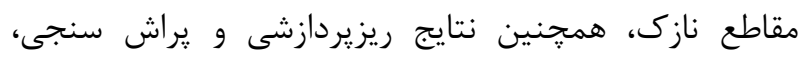

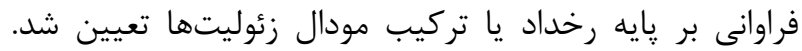

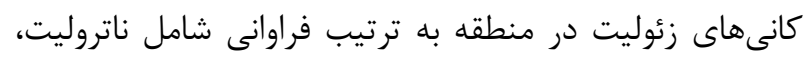

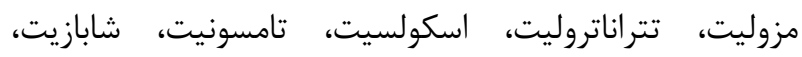
استيلبيت، آنالسيم و ايى استيلبيت هستند كه در ادامه توضيح

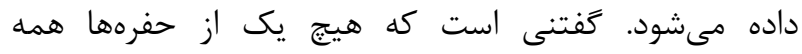

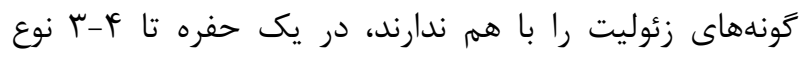
زئوليت ديده شده است.
سنََنًَارى و زمينشيمى سنَ ميزبان زئوليتها

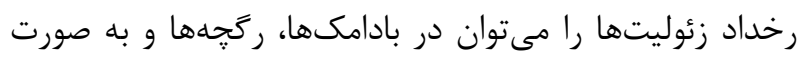

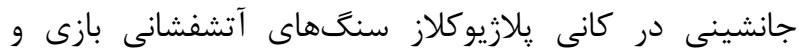
حدواسط منطقه يرندك مشاهده كرد (شكلهاى r ب ب و ").

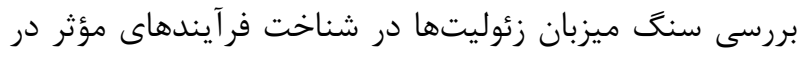

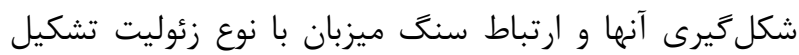
شده الزامى است. سنگهاى بازى و حدواسط ميزبان شامل

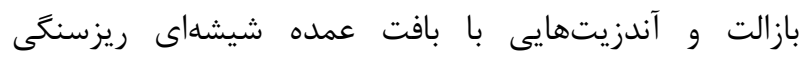
يورفيرى تا كلومرويورفيرى بوده و درشت بلورهاى آن شامل קلازيوكلاز، كلينوييروكسنهاى بدون دخرسانى و اليوينهاى

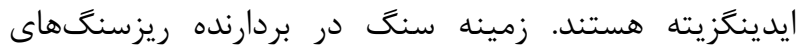

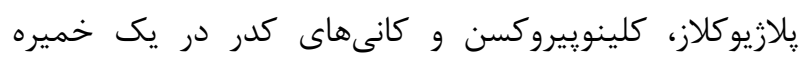
شيشهاى دكرسان شده شامل اكسيدهاى آهن و كلسيت است.

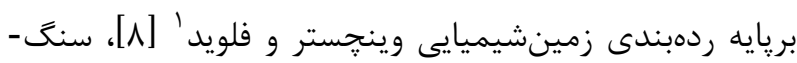
هاى ميزبان زئوليتها در كستره بازالت نيمه قليايى ودئيس و آندزيت 


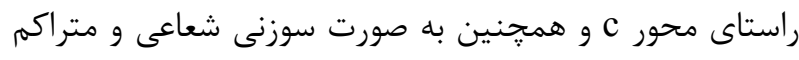

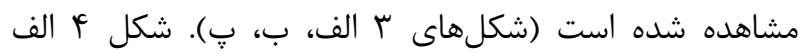

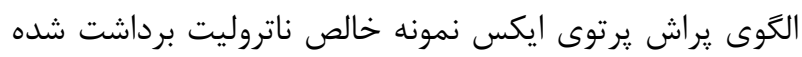

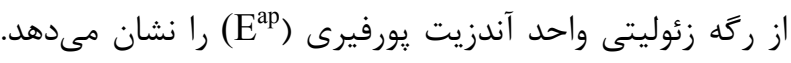

ناتروليت بيشترين فراوانى را در منطقه دارد و در نمونههاى

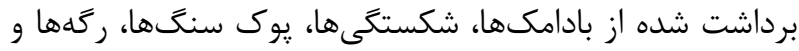

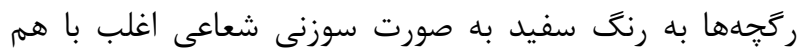

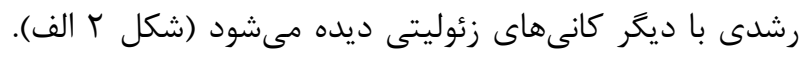
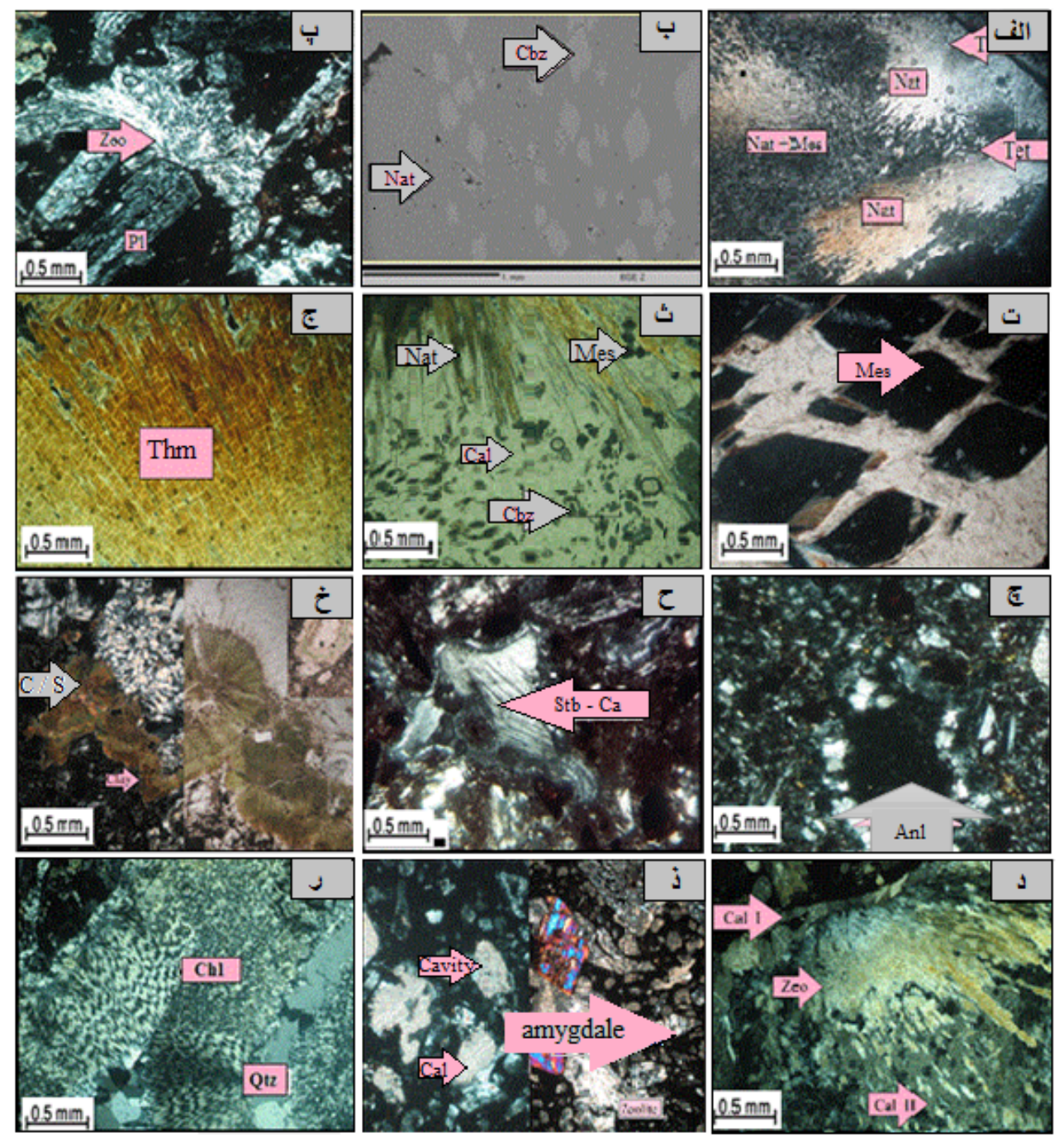

شكل r الف- تصوير ميكروسكويى از زئوليتهاى رشتهاى نمونه برداشت شده از ركَه سنگَهاى بازالتى منطقه يرندك، ب- تصوير ميكروسكوب

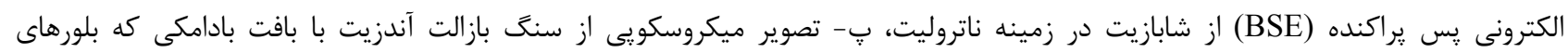

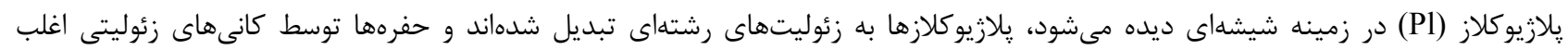

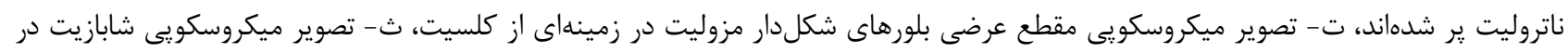

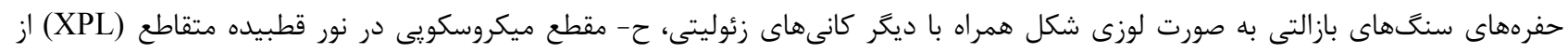

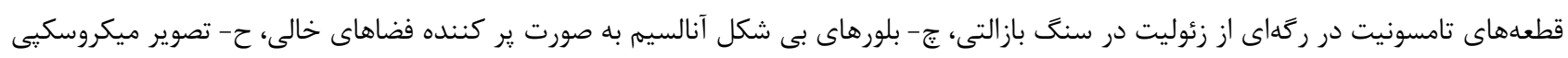

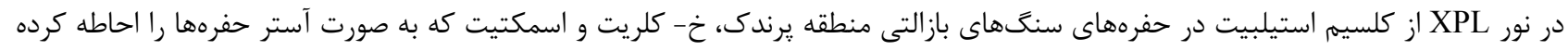

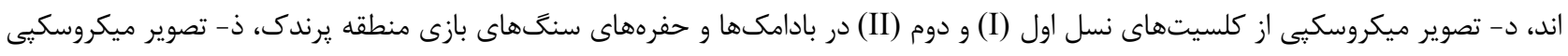

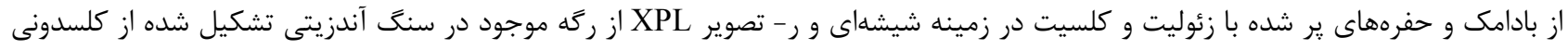

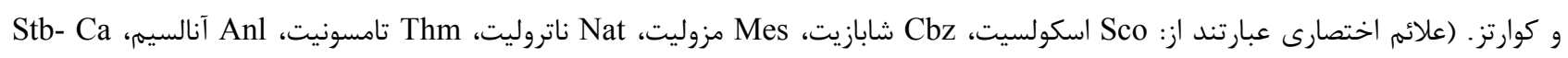

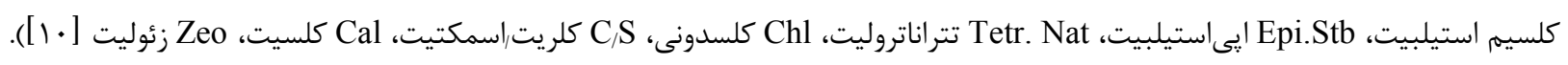




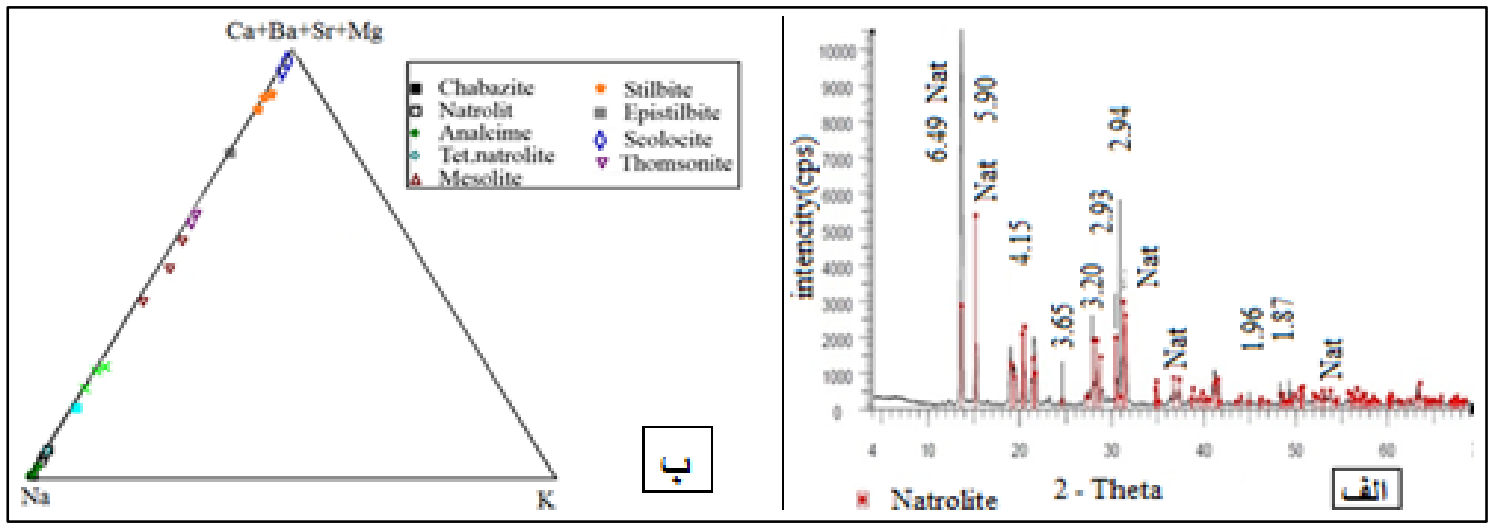

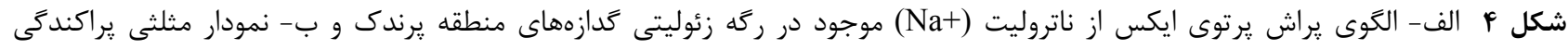

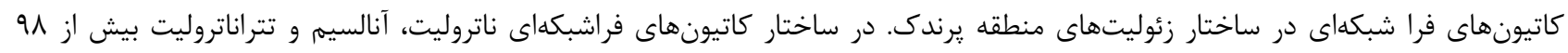

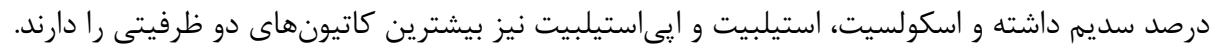

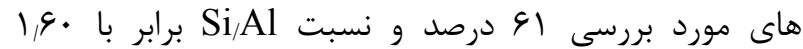

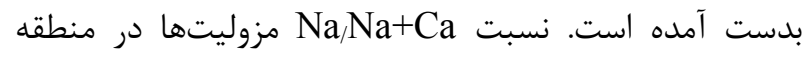

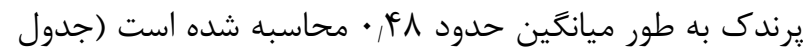

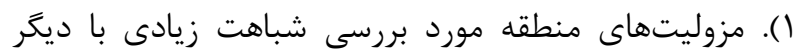

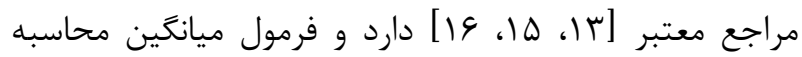
شده براى آنها به صورت $\left(\mathrm{Ca}_{13.52}, \mathrm{Na}_{12.61}, \mathrm{~K}_{0.39}\right)\left[\mathrm{Al}_{46.81} \mathrm{Si}_{74.71} \mathrm{O}_{240}\right] \cdot 64 \mathrm{H}_{2} \mathrm{O}$ است.

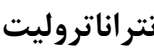

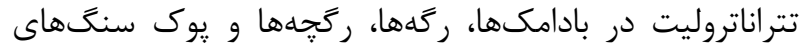

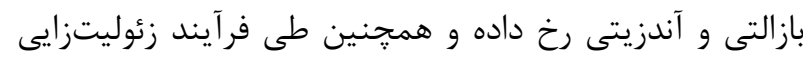

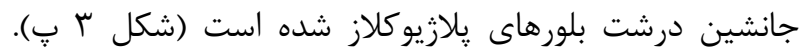

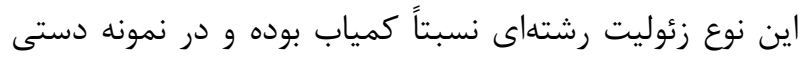

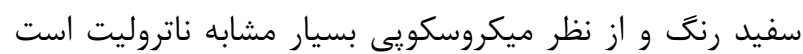

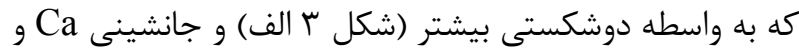

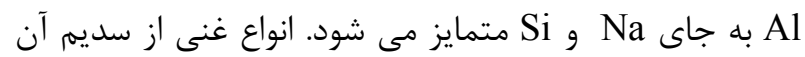

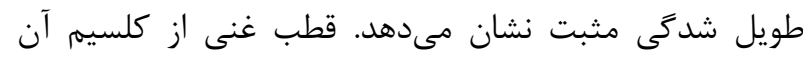

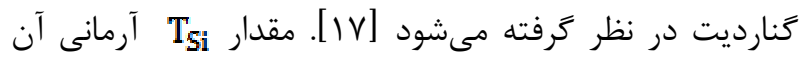

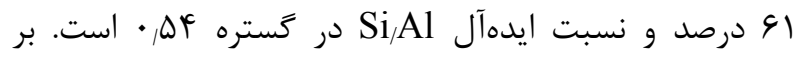

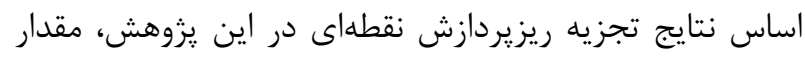

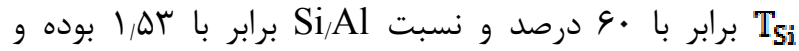

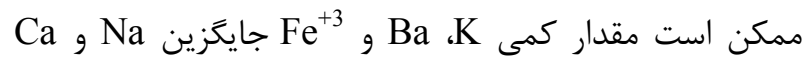
شده باشد (جدول ()). آنها تشابه بسيارى با تتراناتروليتهاى استى

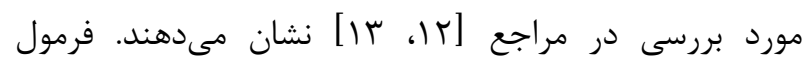

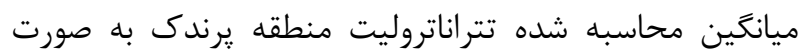
$\left(\mathrm{Na}_{13.02}, \mathrm{Ca}_{1.00}, \mathrm{~K}_{.01}\right)\left[\mathrm{Al}_{15.86} \mathrm{Si}_{24.27} \mathrm{O}_{80}\right] \cdot 16 \mathrm{H}_{2} \mathrm{O}$
بر اساس نتايج تجزيه ريزيردازشى، سديم كاتيون مهمه در

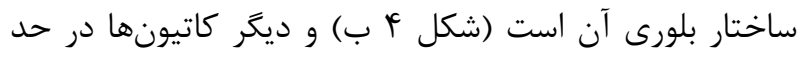

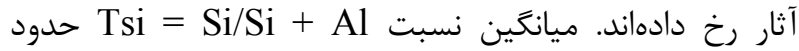

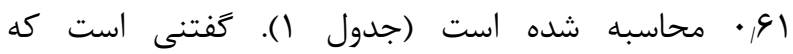

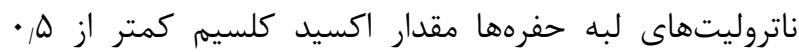

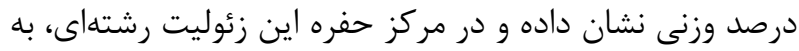

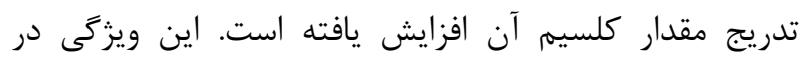

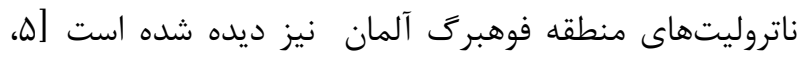

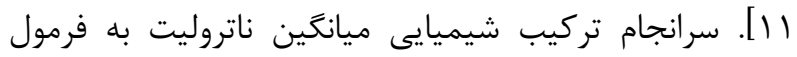

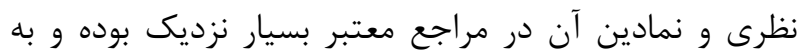

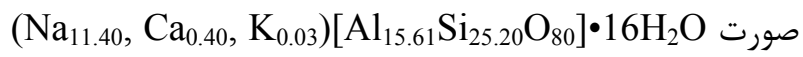

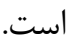
مزوليت مزوليت اغلب در رَّهلها و بادامكهاى سنَّهاى آتشفشانى

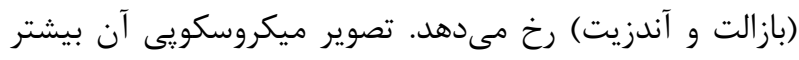

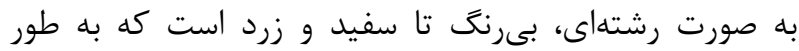

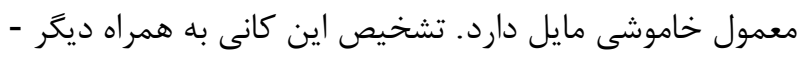

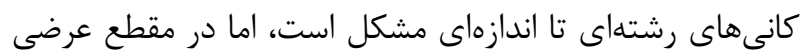

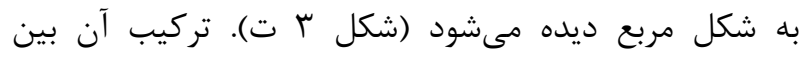

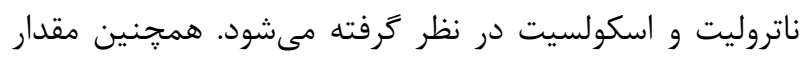
Si

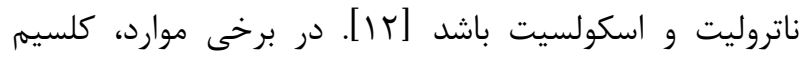

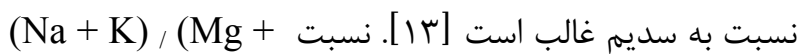
Ca + Sr+ Ba)

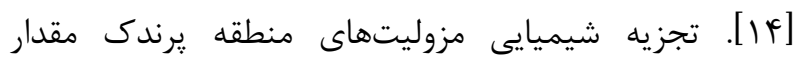
متوسط ونا وزنى نشان داده است. مقدار متوسط lisi براى مزوليت نمونه- 
جدول ا نتايج تجزيه به روش ريزيردازش الكترونى (EPMA) زئوليتهاى معرف موجود در سنگهاى بازى و حدواسط منطقه برندى. (علامت-

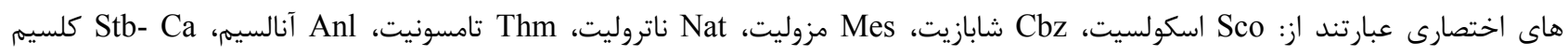

استيلبيت، Epi.Stb إيى استيلبيت، Tetr. Nat تترانتاتروليت).

\begin{tabular}{|c|c|c|c|c|c|c|c|c|c|}
\hline \multirow{3}{*}{ كانى } & \multirow{2}{*}{$\begin{array}{c}\mathrm{Cbz} \\
\mathrm{P5}\end{array}$} & \multirow[b]{2}{*}{ Mes } & \multirow{3}{*}{$\begin{array}{c}\text { Thm } \\
\text { P5 }\end{array}$} & \multirow{3}{*}{$\begin{array}{l}\text { Nat } \\
\text { P16 }\end{array}$} & \multirow{3}{*}{\begin{tabular}{|c|} 
Tetra. Nat \\
P5
\end{tabular}} & \multirow[b]{2}{*}{ Epi. stb } & \multirow[b]{2}{*}{ Anl } & \multirow[b]{2}{*}{ Stb-Ca } & \multirow[b]{2}{*}{ Sco } \\
\hline & & & & & & & & & \\
\hline & P5 & P16 & & & & P5 & P5 & P16 & P5 \\
\hline $\mathrm{SiO}_{2}$ & $\Delta \cdot, 1 \Lambda$ & $k q, k r$ & $f \Delta, q r$ & $\Delta 1, \pi r$ & $q v, q v$ & $\Delta \cdot \theta$ & $\Delta r, q 1$ & $\Delta 9,9 r$ & $r q, \cdot r$ \\
\hline $\mathrm{TiO}_{2}$ & $\cdot . \cdot 1$ &. .1 & $\cdots$ &.$\cdot 1$ &.$\cdot 1$ & $\cdot \cdot \cdot$ & $+\cdot$ & 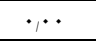 & $\cdot \cdot \cdot$ \\
\hline $\mathrm{Al}_{2} \mathrm{O}_{3}$ & $r 1, q r$ & $r g, \mid r$ & $r \varepsilon q$. & $T V_{1} \cdot \Delta$ & $r \Delta, v q$ & 19.1 & $T Y, \wedge \Delta$ & $1 V_{1} \cdot 1$ & $r 9, \cdot 1$ \\
\hline $\mathrm{FeO}$ & $\cdot . \cdot 1$ & $\cdot . \cdot 1$ & $\cdot \cdot \cdot r$ & $\cdot \cdot \cdot$ & $\cdot \cdot \cdot 1$ & $\cdot, \cdot$ &..$r$ & $\cdot, \cdot$ & $\cdot \cdot \cdot 1$ \\
\hline MnO & $\ldots$ & $\ldots$ & $\ldots$ & $\ldots$ & $\ldots$ & $\ldots$ & $\ldots$ & $\ldots$ & $\ldots$ \\
\hline MgO &.+ & .1. & $\cdot \cdots$ &.,$\cdot 9$ &.$\cdot 1$ & $\because \cdot V$ &., $4 \Lambda$ & 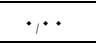 &.$\cdot r$ \\
\hline $\mathrm{CaO}$ & $1 \%$, 99 & $\Lambda, \Gamma \Delta$ & $11, \pi$ & .99 & $1, \Delta 9$ & $9, \Delta$. &., 49 & $\Lambda_{1} \cdot r$ & $\mid r, r$ \\
\hline $\mathrm{Na}_{2} \mathrm{O}$ & .1. & $r, \| r$ & $r, r q$ & $1 \pi, r$ & $1 \pi, \pi r$ & 1,91 & $I r, V r$ & $\cdot, v 1$ &.,$\pi 1$ \\
\hline $\mathrm{K}_{2} \mathrm{O}$ & $\cdot \cdot r$ & .119 & $\cdot \cdot r$ &.,$\cdot 9$ & $\cdot \cdot \cdot 1$ & $\because \cdot r$ &.$/ 99$ & $\because \cdot 1$ &.$\cdot 1$ \\
\hline $\mathrm{BaO}$ & 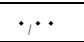 &., 1 &., 1 &..$\cdot$ & $\cdot \cdot \cdot$ & 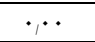 & 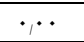 & $\because \cdot V$ & 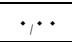 \\
\hline مجموع & $19,9 \Lambda$ & $M \Lambda, r r$ & $\Delta V, V I$ & 9.91 & $\mu_{1}, \varepsilon$. & $V V_{A} A T$ & $91,4 \mathrm{~V}$ & $\Lambda T \Delta \Delta$ & $\Lambda N_{1}+9$ \\
\hline o & TF & rF. & $\Lambda \cdot$ & $\wedge$. & $\wedge \cdot$ & 99 & 99 & Vr & $\wedge$. \\
\hline \multicolumn{10}{|l|}{ كاتيونها } \\
\hline $\mathbf{S i}$ & $V, \wedge F$ & $v \Delta$ & $r \mu, V$ & $r \Delta, 1 \varphi$ & $r F, \Delta q$ & TH, KT & $r 1,11$ & $r g, V T$ & $T F, V D$ \\
\hline Al & $r, 91$ & $r g, V T$ & 19,49 & $\mid \Delta, \Delta f$ & $\mid Q, \Delta \Lambda$ & $I T, A T$ & $I V, K r$ & 9,44 & $10, i \wedge$ \\
\hline $\mathbf{T i}$ & 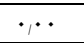 & $\cdot, \cdot 1$ & 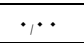 & $\cdot . \cdot 1$ & $\cdot, \cdot$ & 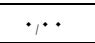 & $\cdot, \cdot$ & $\cdot \cdot \cdot$ & $\cdot, \cdot$ \\
\hline $\mathbf{F e}$ & 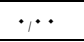 &. .1 & 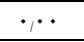 &.+ & $\cdot \cdot \cdot$ & 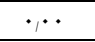 &.$\cdot 1$ & 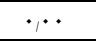 & $\cdot \cdot \cdot$ \\
\hline Mn & 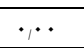 & 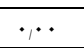 &.. & 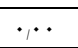 & $\cdot \cdot \cdot$ & $\cdot . \cdot$ &.+ & 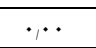 & 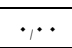 \\
\hline Mg & 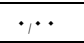 & 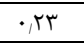 & $\cdot \cdot$ &.$\cdot 1$ &.$\cdot 1$ & $\because \cdot V$ &., $4 r$ & 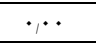 & $\cdot \cdot \cdot r$ \\
\hline $\mathrm{Ca}$ & $T, \pi r$ & $|r, \mu|$ & 9,49 & $\cdot, V \varphi$ & $\cdot \wedge 9$ & 9,95 &.,$\pi \Delta$ & $f, \theta$ & $V, 1 f$ \\
\hline $\mathrm{Na}$ & $\cdot \cdot r$ & $|r| r$, & $r, 4 q$ & 11,9 & $\mid \pi / 10$ & $r, r I$ & $I f, \Delta r$ & $9 \Delta_{j}$. & $\cdot r$. \\
\hline $\mathrm{K}$ &.$r$ & $\cdot r V$ &. .1 & $\cdot \cdot r$ &. .1 &.$\cdot 1$ & $\cdot \cdot \cdot$ &.$\cdot 1$ &.. \\
\hline $\mathbf{B a}$ & ${ }^{\prime}, \cdot$ & ${ }^{\prime}, \cdot$ & $\ldots$ & 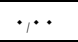 & ${ }^{\prime} \cdot \cdot$ & 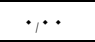 & ${ }^{\prime} \cdot \cdot$ &., 1 & ${ }^{\prime}$. \\
\hline Tsi & .99 & .91 & $\cdot 09$ &.,$g r$ & .91 & $\cdot V r$ &.,$g 4$ & $\cdot V^{k}$ & .91 \\
\hline $\mathbf{S i} / \mathbf{A l}$ & $1,9 \mathrm{~V}$ & 1,91 & $1,4 \Delta$ & 1,95 & $1, \Delta \Lambda$ & 1,91 & $1, \wedge 1$ & $r, \lambda r$ & $1,9$. \\
\hline $\mathrm{Na}_{/} \mathrm{Na}+\mathrm{Ca}$ &.$\cdot 1$ & 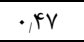 &.,$\pi \Delta$ & .99 & .94 &.,$\pi r$ & .91 & .114 &.$\cdot r$ \\
\hline
\end{tabular}

\section{$\mathrm{T}_{\mathrm{Si}}=\mathrm{Si}(\mathrm{Si}+\mathrm{Al})$}

برآمده از تجزيه تامسونيتهاى منطقه يرندك با دستخاه ريز كاو

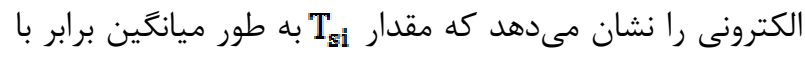

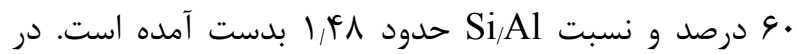

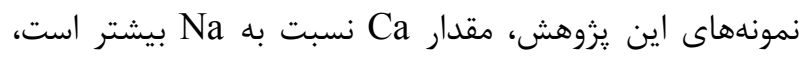

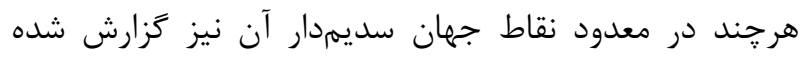

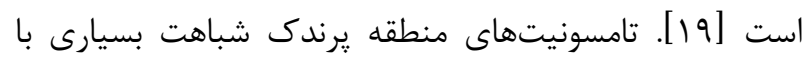

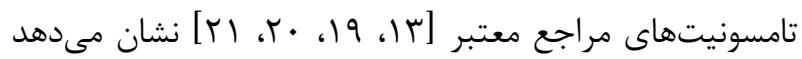

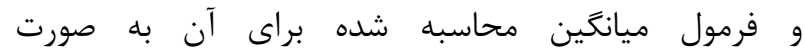
$\left(\mathrm{Ca}_{6.62}, \mathrm{Na}_{3.29}, \mathrm{~K}_{0.01},\right)\left[\mathrm{Al}_{16.06} \mathrm{Si}_{23.63} \mathrm{O}_{80}\right] \cdot 24 \mathrm{H}_{2} \mathrm{O}$

\section{اسكولسيت}

بلورهاى اسكولسيت در نمونه دستى شفاف تا سفيد رنك

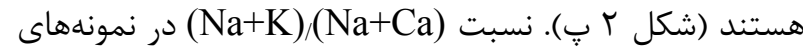

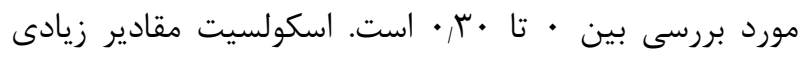

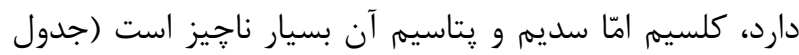

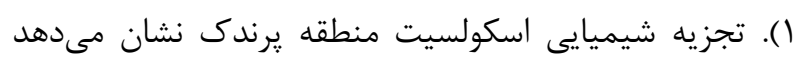

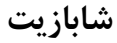

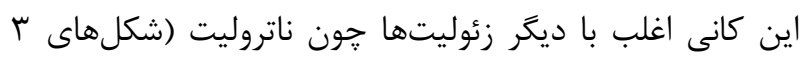

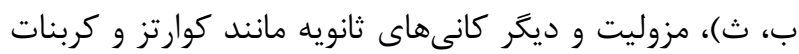

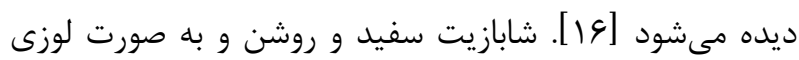

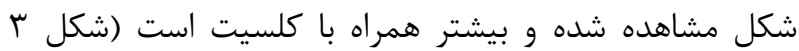

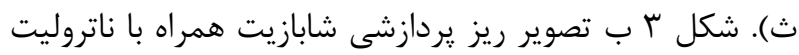

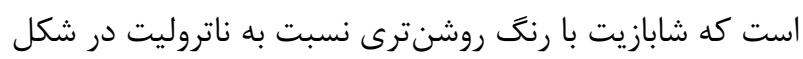

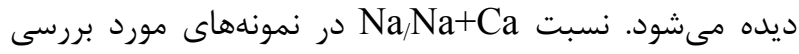

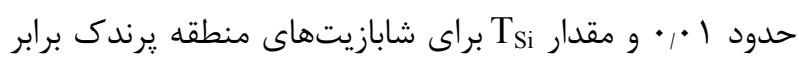

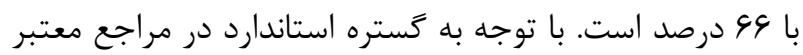

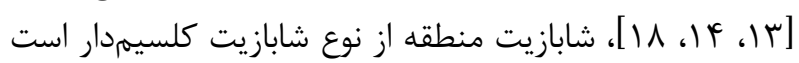
و فرمول بدست آمده براى آن به صورت آنازي است. $\left(\mathrm{Ca}_{1,9}, \mathrm{Na}_{0.4}\right)_{4}\left[\mathrm{Al}_{4.3} \mathrm{Si}_{7.8} \mathrm{O}_{24}\right] 12 \mathrm{H}_{2} \mathrm{O}$ تامسونيت تامسونيت به صورت قطعههاى بلورى (شكل r ج ج)، مسطح و

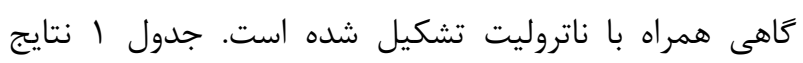




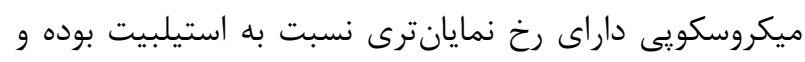

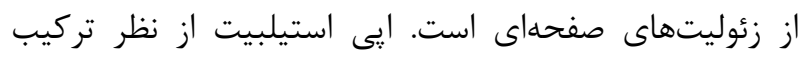

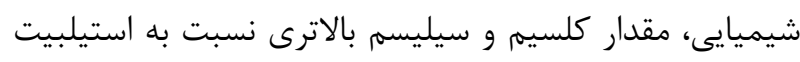

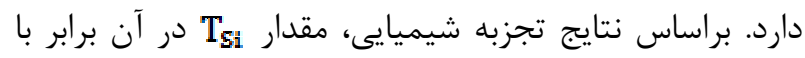

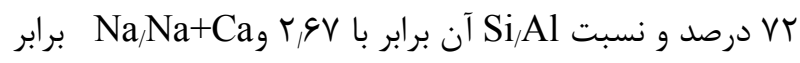

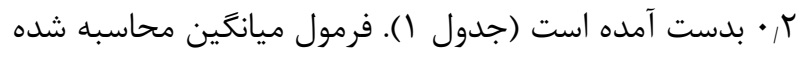

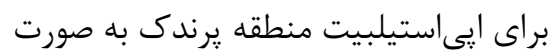
است. $\left(\mathrm{Na}_{2.21}, \mathrm{Ca}_{6.91 .78}, \mathrm{~K}_{0.01}\right)\left[\mathrm{Al}_{12.81} \mathrm{Si}_{34.32} \mathrm{O}_{96}\right] \cdot 32 \mathrm{H}_{2} \mathrm{O}$

\section{ديگر كانىهاى ثانويه}

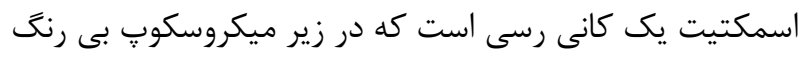

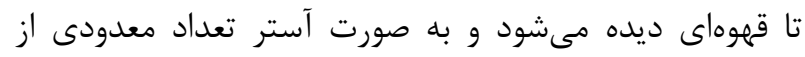

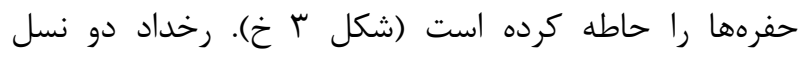

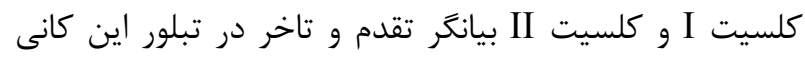

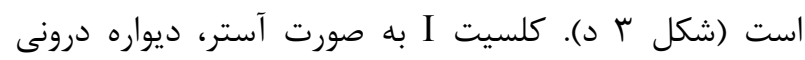

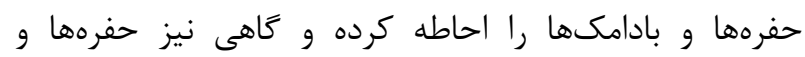

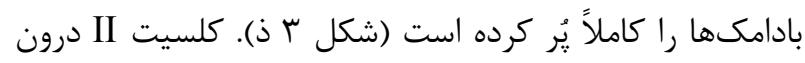

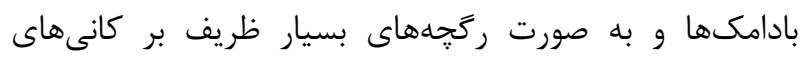

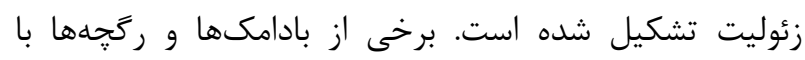

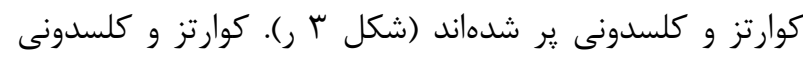

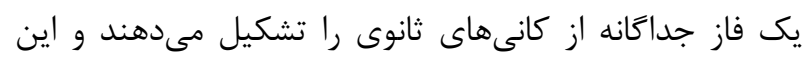

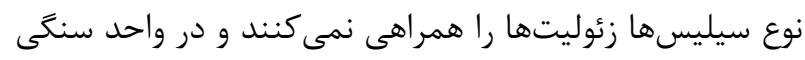

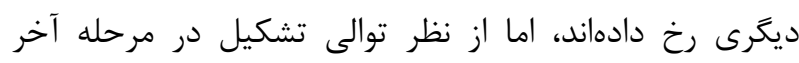
تشكيل كانىهاى ثانوى قرار دارند.

نتايج اين بررسى نشان داد كه در منطقه يرندى، تنوع بسيارى

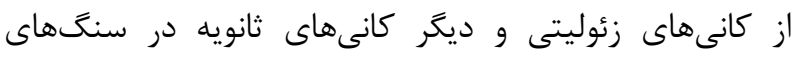

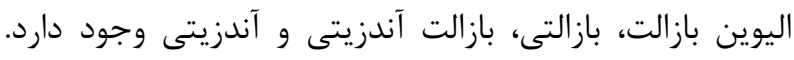

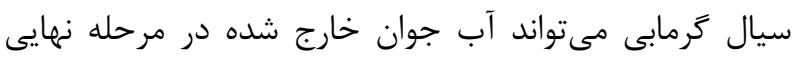

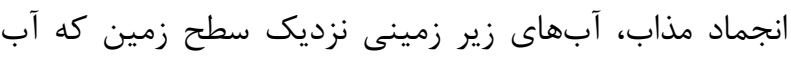

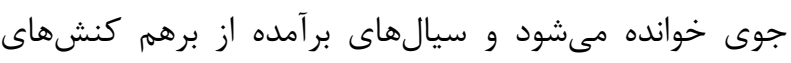

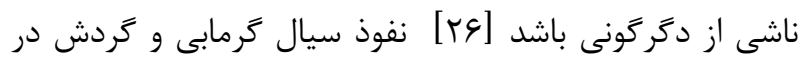

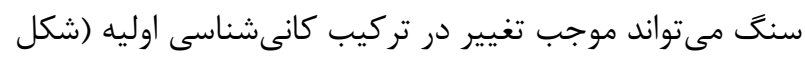

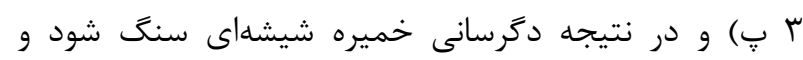

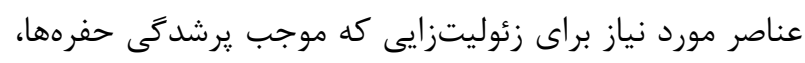

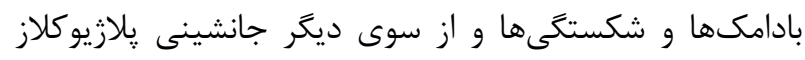

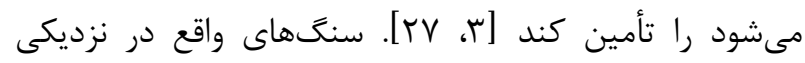

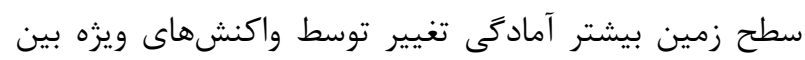

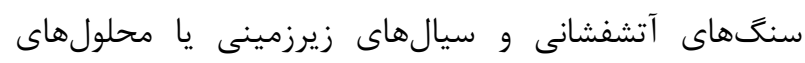

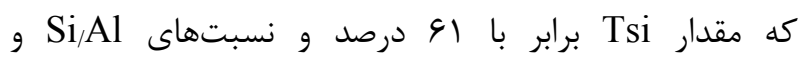
(Na+K)(Na+Ca)

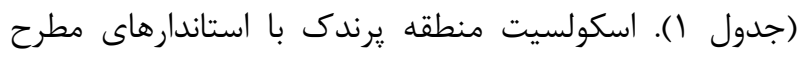

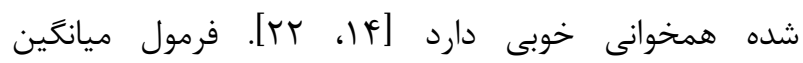
اسكولسيت منطقه يرندك به صورت $\left(\mathrm{Ca}_{7.78}, \mathrm{Na}_{0.2} \mathrm{Mg}_{0.02}\right)\left[\mathrm{Al}_{15.52} \mathrm{Si}_{24.75} \mathrm{O}_{80}\right] \cdot 24 \mathrm{H}_{2} \mathrm{O}$

آنالسيم

آنالسيم به عنوان يركننده حفرهها (شكل r ج) در حاليكه در لبه درونى حفرههاى سنگهاى آذرين بازى و حدواسط (بازالت

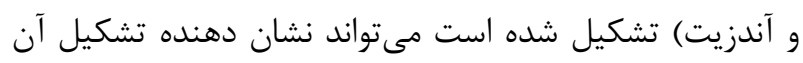

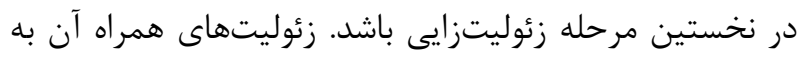

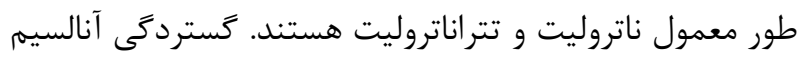

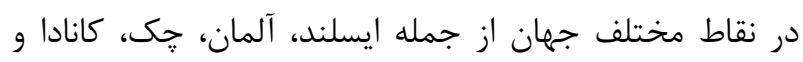

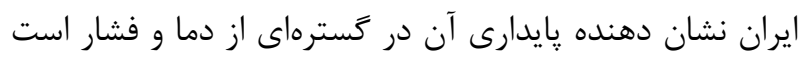

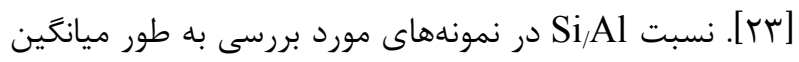

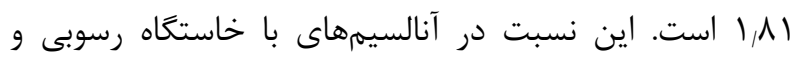

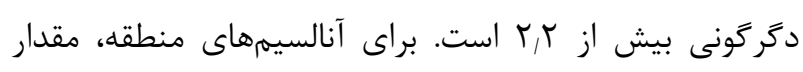

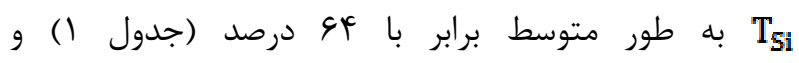

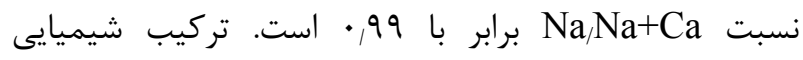
آنالسيمهاى موجود در منطقه با مراجع $\left(\mathrm{Na}_{14.69}, \mathrm{Ca}_{0.14}, \mathrm{Mg}_{0.2}\right)\left[\mathrm{Al}_{17.25} \mathrm{Si}_{31.21} \mathrm{O}_{96}\right] \cdot \mathrm{H}_{2} \mathrm{O}$

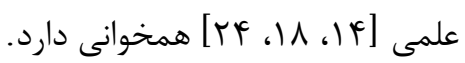
استيلبيت استيلبيت به صورت بلورهاى صفحهاى شكل اغلب در حفرههاى سنگ هاى بازى منطقه مورد بررسى تشكيل شده است. آنها

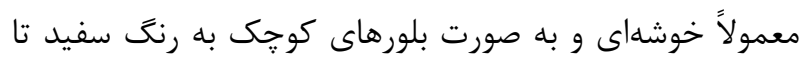

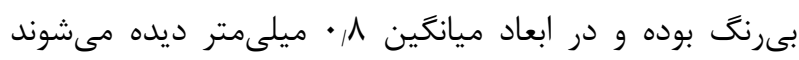

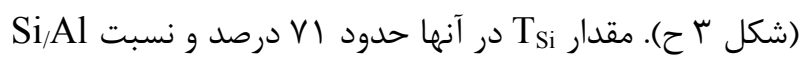

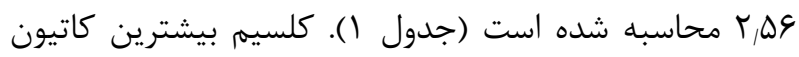

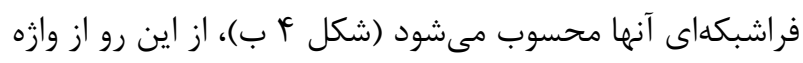

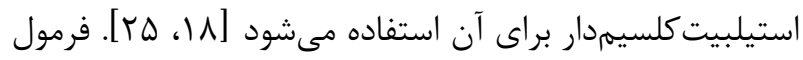

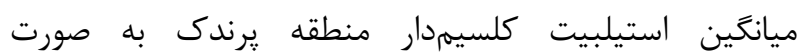
$\left(\mathrm{Ca}_{5.78}, \mathrm{Na}_{0.67}, \mathrm{~K}_{0.03}, \mathrm{Mg}_{0.01}\right)\left[\mathrm{Al}_{9.82} \mathrm{Si}_{25.54} \mathrm{O}_{72}\right] \cdot 28 \mathrm{H}_{2} \mathrm{O}$ بدست آمده است. ايبى استيلبيت اين كانى بسيار كمياب بوده و در شمال شرق منطقه يرندى

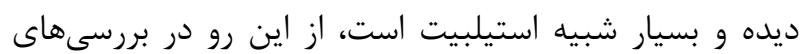




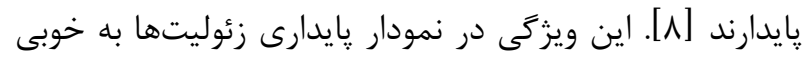

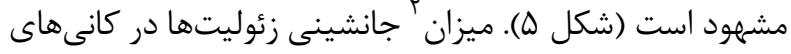

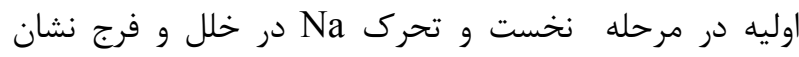
دهنده تحرك بالاى عناصر است. تشكيل زئوليتهاى غنى آنى از

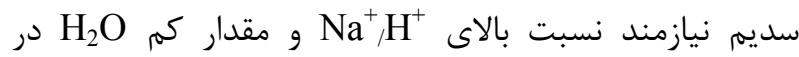
محيط است (شكل ه هِ). همجنين نسبت Si/Al در تعيين نوع و تركيب زئوليتها

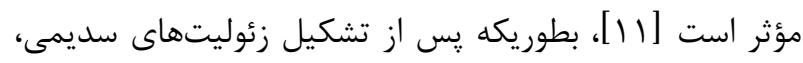
كاهش آلكالينيته سيال سبب تشكيل زئوليتهاى مرحله دوم

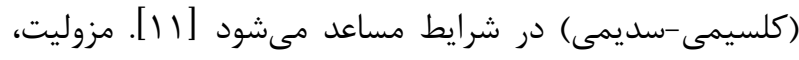

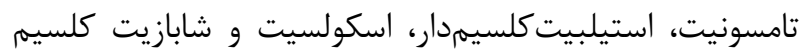

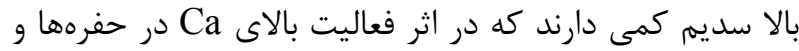

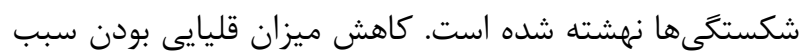

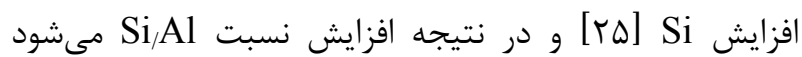
(شكل 9 الف).

شكل \& الف كستره وسيعى از نسبت Si/Al و كاتيونهاى

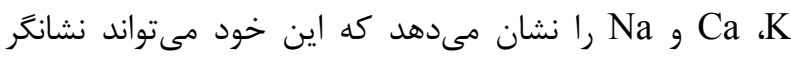
مراحل مختلف محلول كرمابى در تشكيل آنها باشد. شكل عاد يك طرح به نسبت ساده همبرزايى براى زئوليتها و و كانى هاى

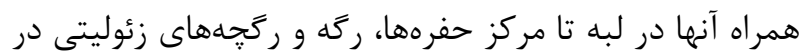
مقاطع مورد بررسى را نشان مى دهد اندي.

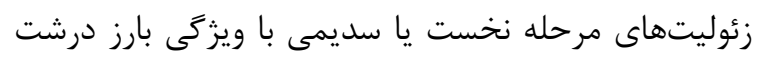

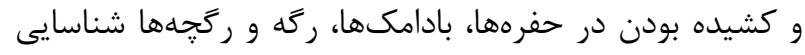

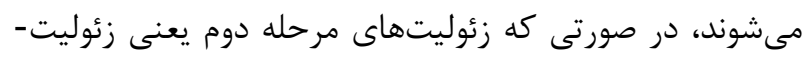

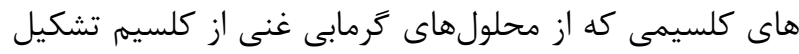

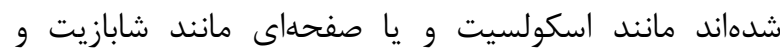

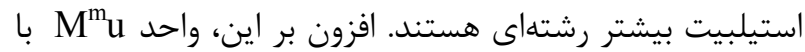

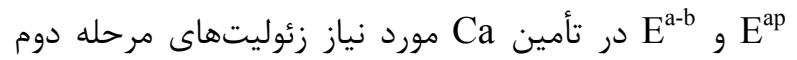

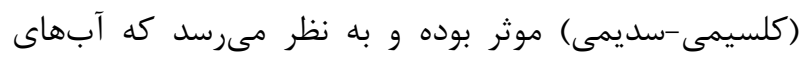

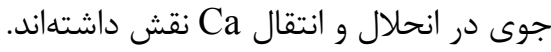

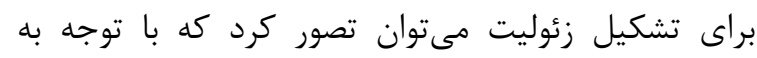

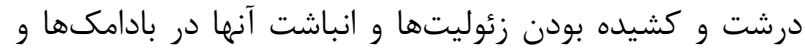

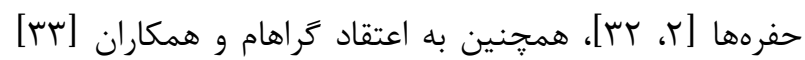

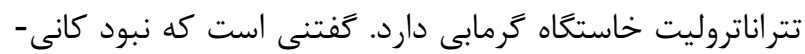

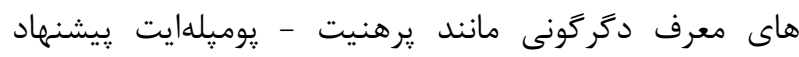

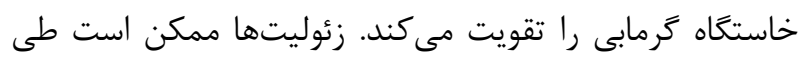

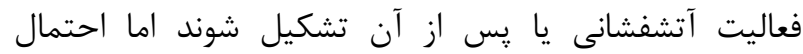

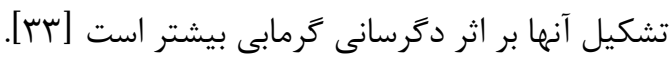

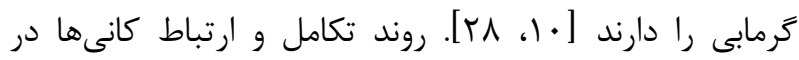

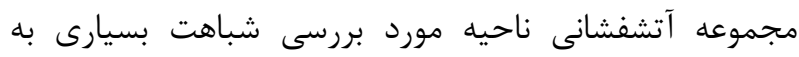

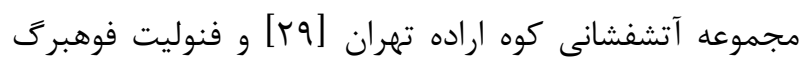

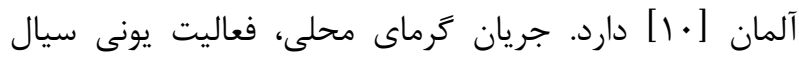

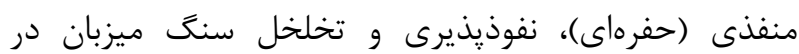

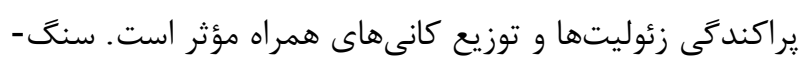
هاى آندزيت و بازالت يورفيرى (واحد

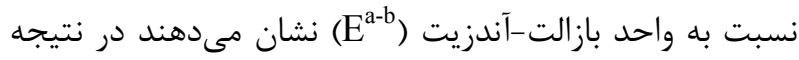

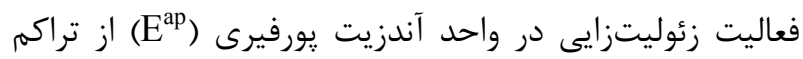

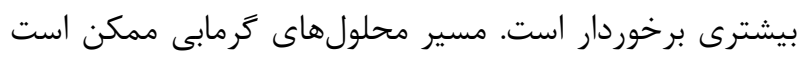

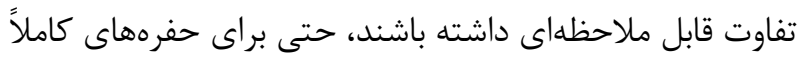

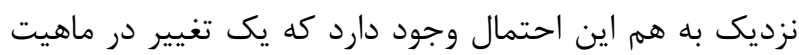

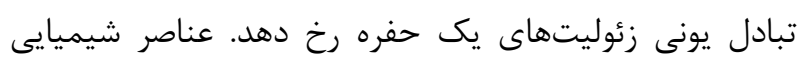

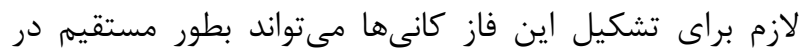

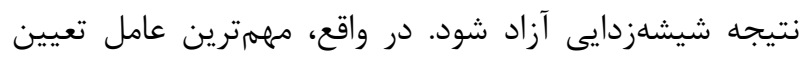

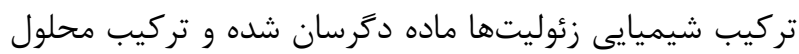

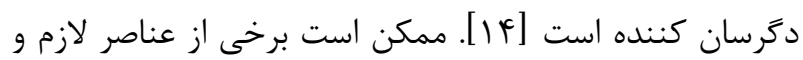

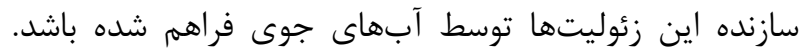

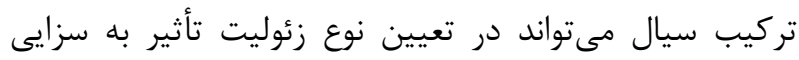

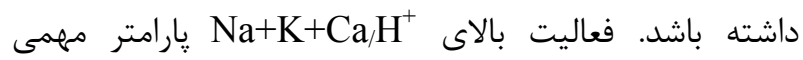
محسوب مىشود، همجنين pH بيش از 9 سرعت تشكيل

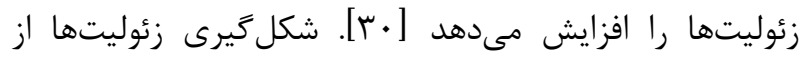

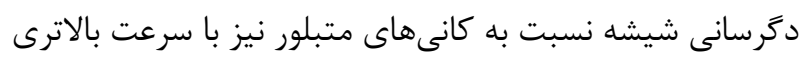

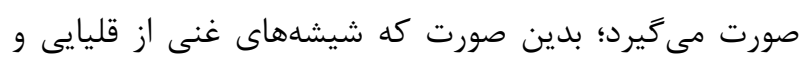

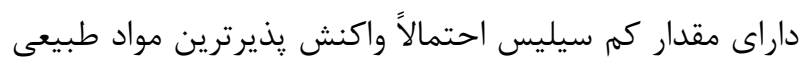

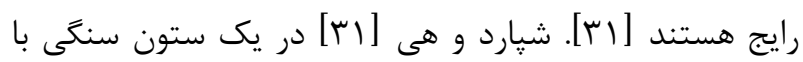

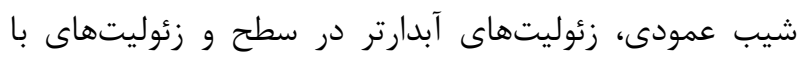

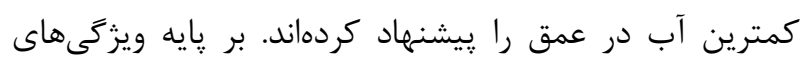

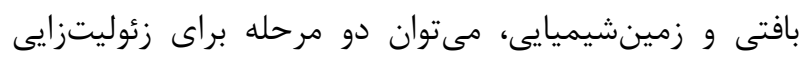

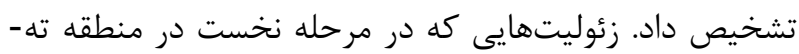

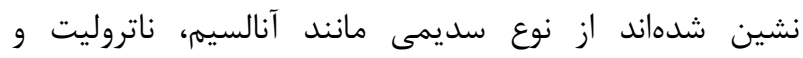

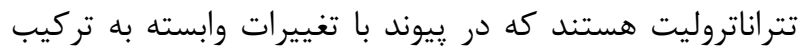

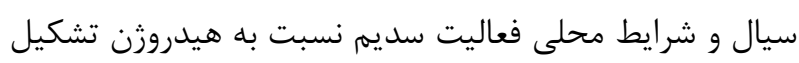

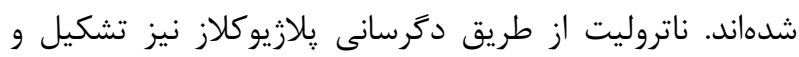

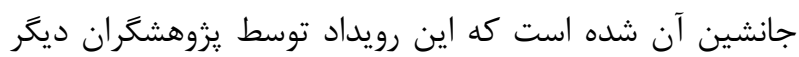

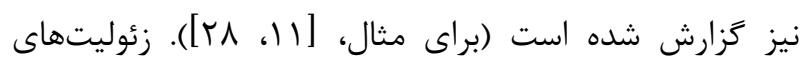

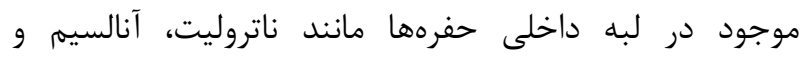

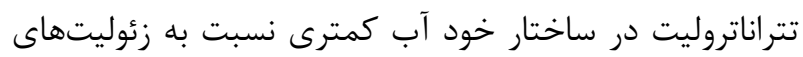

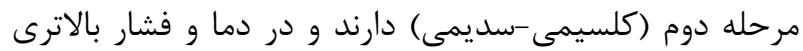



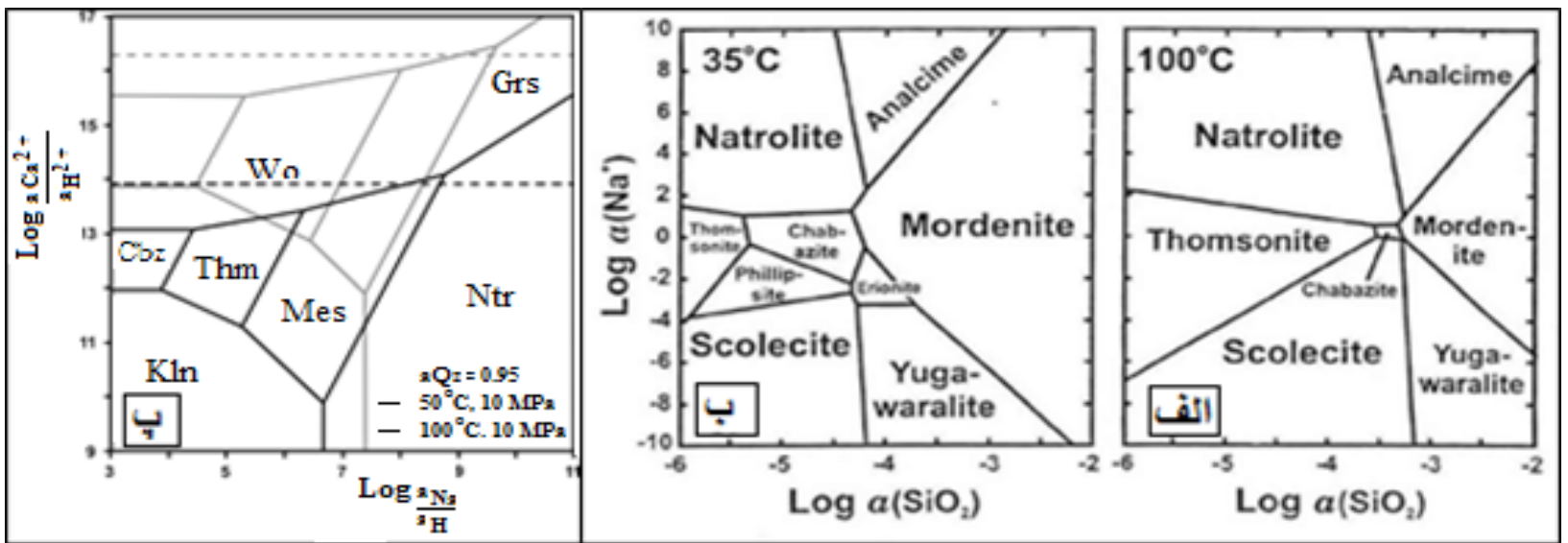

شكل هـ الف- نمودار

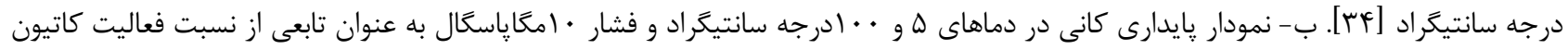
در سامانه al دانه (علائم اختصارى عبارتند از: Wo ولاستونيت، Ntr ناتروليت، Kln كائولينيت، Grs گروسولار، Mes مزوليت،

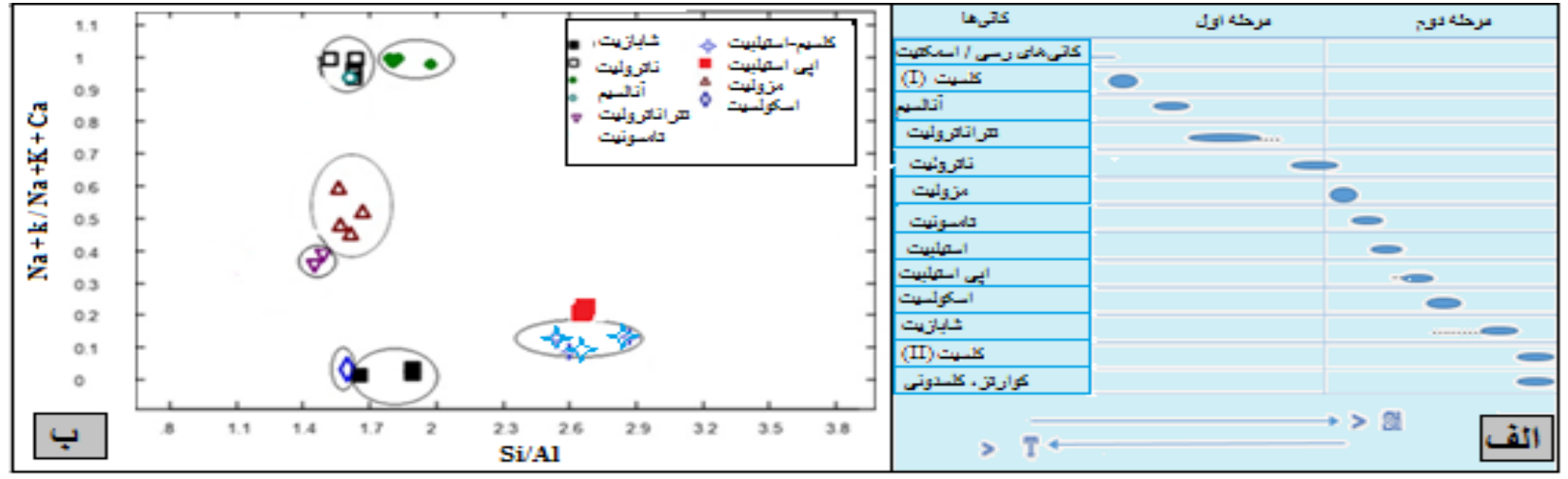

شكل 9 الف- نمودار Si/Al نسبت به Na+K/Na+K+Ca براى تعيين تركيب زئوليتها در منطقه يرندك كه تغييرات كستردهاى را در نسبت

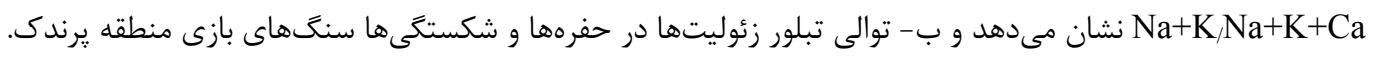

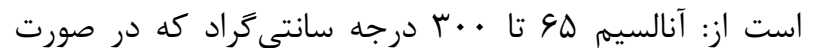

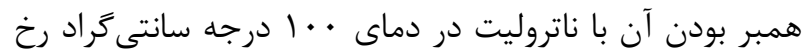

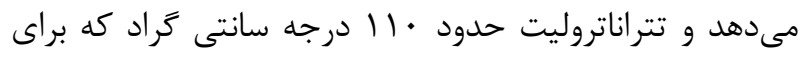

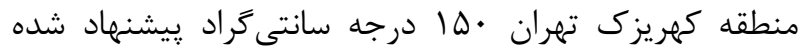

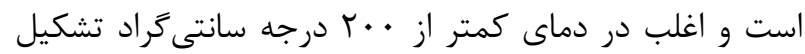

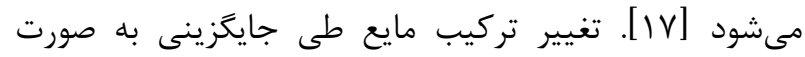
تابعى از فعاليت سليس محلول و

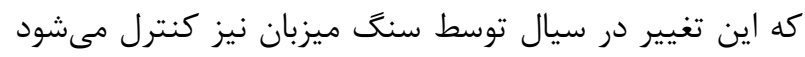

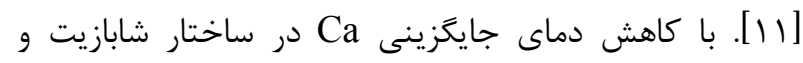

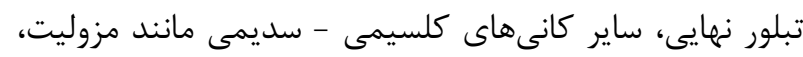

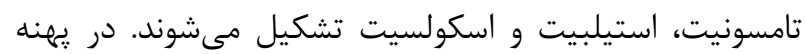

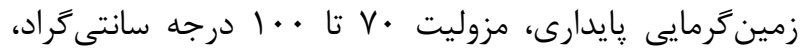

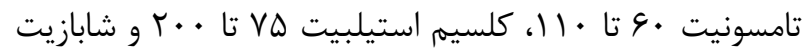

فعاليت بالاى CO $\mathrm{CO}_{2}$ در سيال شامل Ca مىتواند منجر به

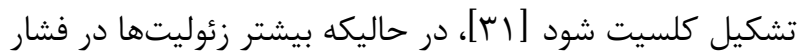
يايين فازهاى غنى از سيليس مانند كوارتز و كلسدونى (شكل

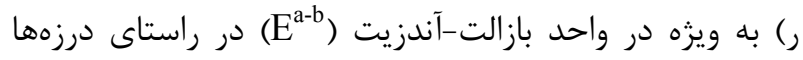

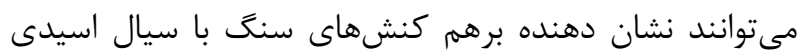

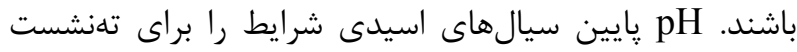

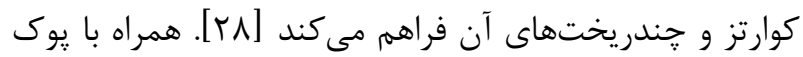

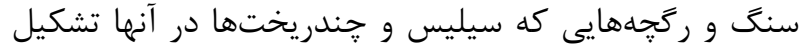
شدهاند هيج كونه زئوليتى ديده نمى شود.

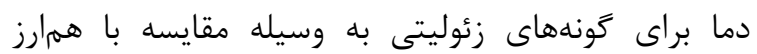

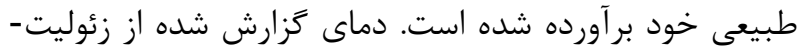

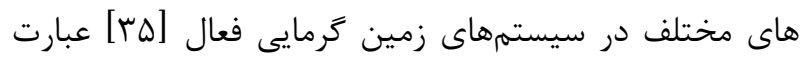


[5] Weisenberger T., Spurgin S., "Zeolite in alkaline rocke of the Kasersyuhl volcanic complex, SW Germany-new microprobe investigation and elationship of zeolite mineralogy to the host rock", Gealogica Belgica 12 (2009) 75-91.

[6] Aqanbati A., "Geology of Iran", Geological Survey of Iran Geological organization and mineral exploration of Iran (2004) 582 pages.

[7] Amidi M., "Geological map 1,100000 Zavieh" Geological organization and mineral exploration of Iran (2005).

[8] Triana J. M., Herrera J. F., Rios C. A., Castellanos O. M., Henao J. A., Williams C., Roberts C., "Natural zeolites filling amygdales and veins in basalts from the British Tertiary Igneous Province on the Isle of Skye, Scotland", Earth Scinces 16(1) (2012) 41-53.

[9] Winchester J. A., Floyd P. A., "Geochemical discrimination of different series and their differentiation products using immobile elements", Chem. Geology 20(4) (1977) 325-343.

MacDonald G. A. "Composition and Origin of Hawaii Lavas", Geological Society of America Memoirs 116 (1968) 477-522.

[10] Weisenberger T. B., Spurgin S., Lahaye Y., "Hydrothermal alteration and zeolitization of the Fohberg phonolite, Kaiserstuhl Volcanic Complex, Germany", International Journal Earth Science (Geology Rundsch) 103 (2014) 2273-2300.

[11] Ross M., Flohr M. J. K., Ross D. R., "Crystalline solution series and order-disorder within the natrolite mineral group", American. Mineral 77 (1992) 685-703.

[12] Passaglia E., Sheppard R. A., "The Crystal Chemistry of Zeolites. In: Natural Zeolites: Occurrence, Properties, Applications"

Mineralogical Society of America Geochemical Society 45 (2001) 69-116.

[13] Deer W., Howie R., Zussman J., Wise W., "Rock Forming Minerals, 4B. Framework Silicates: Londres. Gran Bretana" The Geological Society, 2a Edicion, (2004) 982p.

$$
\begin{aligned}
& \text { ها تا • ها درجه تشكيل شدهاند [با]]. با توجّه به نوع زئوليت- }
\end{aligned}
$$

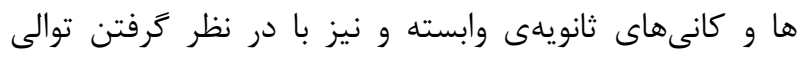

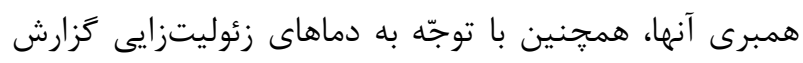

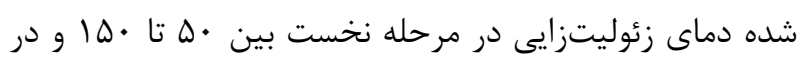

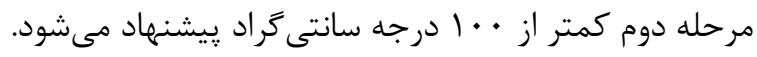

$$
\begin{aligned}
& \text { برداشت }
\end{aligned}
$$

توالى زئوليتها و كانىهاى همراه آنها در بادامكها، ر ركهها و

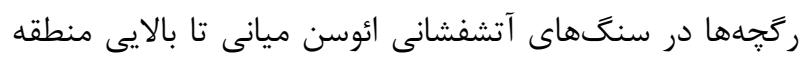

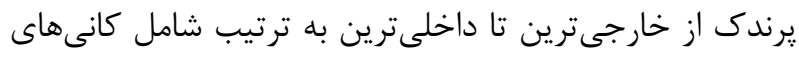

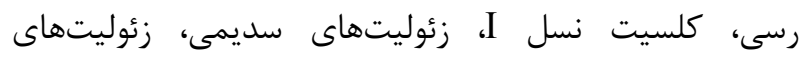

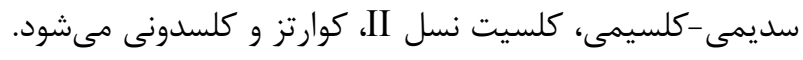

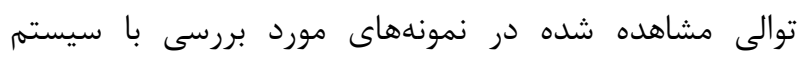

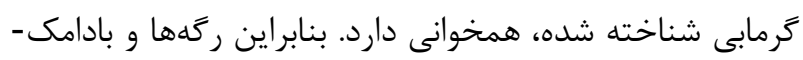

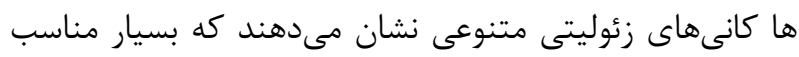

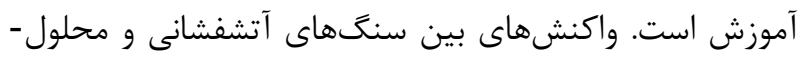

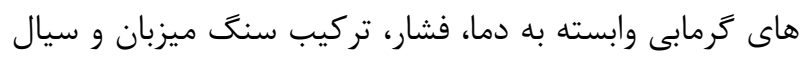

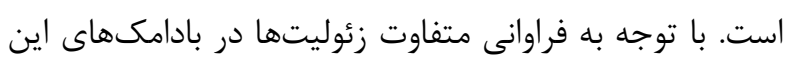

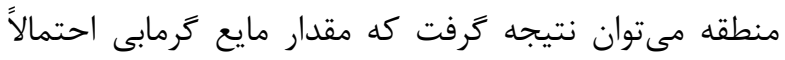

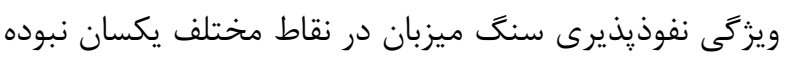

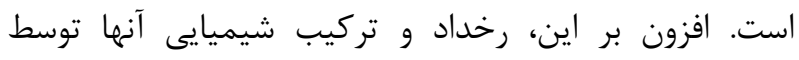

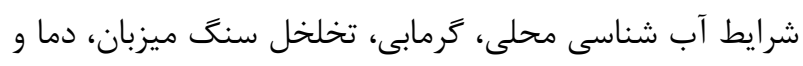

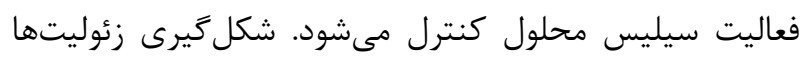

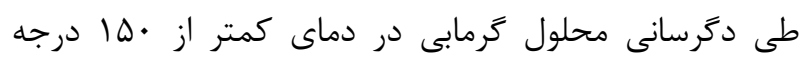

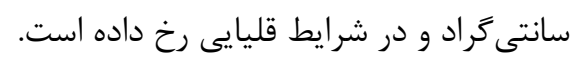
مراجع

[1] Bazargani-Guilani K., Rabbani M. S., Irajian A. A., "A review on Natural zeolites of Iran", Joint Meeting of The Geological Society of America (2008) 54-130.

[2] Gottardi G., Galli E., "Natural zeolites", Springer, Berlin, Heidelberg, New York, Tokyo, (1985) 409.

[3] Weisenberger T., Selbekk R. S., "Multi-stage zeolite facies mineralization in the Hvalfjo rdur area, Iceland", Journal Earth Scince (Geol. Rundsch) 98 (2009) 985-999.

[4] Weisenberger T., Bucher K., "Zeolites in fissures of granites and gneisses of the Central Alps", Journal of metamorphic Geology 28 (2010) 825-847. 
[22] Neuhoff P. S., Hovis G., Balassone G. Stebbine J. F., "Thermodynamic properties of analcime solid solutions", American Journal of Science 304 (2004) 21-66.

[23] Karlsson H. R. Clayton R. N., "Analcime phenocrysts in igneous rocks: Primary or secondary", American Mineralogist 76 (1991) 189199.

[24] Chipera, S., Apps, J., "Geochemical stability of natural zeolites" , Mineralogical Society of America 45 (2001) 117-161.

[25] Whitney D. L., Evants, B. W., "Abbreviations for names of rock - foring inerals", American Mineralogist 95 (2010) 185-187.

[26] Weisenberger T., Bucher K., "Mass transfer and porosity evolution during low temperatureWater-rock interaction in gneisses of the simano nappe: Arvigo, Val Calanca, Swiss Alps", Contrib Mineral Petrol 162 (2011) 61-81.

[27] Neuhoff P.S., Fridriksson T., Arnorsson S., "Porosity evolution and mineral paragenesis during low-grade metamorphism of basaltic lavas at Teigarhorn, Eastern Iceland", American Journal of Science 299 (1999) 467-501.

[28] Kousehlar M., Weisenberger T. B., Tutti F., Mirnejad H., "Fluid control on low temperature mineral formation in volcanic rocks of Kahrizak, Iran", Geofluids 12 (2012) 295-311.

[29] Taylor M. W., Surdam RC., "Zeolite reaction in tuffaceous sediments TeelsMarsh, Nevada", Clays and Clay Minerals 29 (1981) 341-352.

[30] Sheppard R., Hay R., "Occurrence of zeolites in sedimentary rocks", Mineralogical Society of America 45 (2001) 217-234

[31] Lagat J., "Hydrothermal alteration mineralogy in geothermal fieldes with case examples from Olkaria Domes geothermal field, Kenya", Presented at Short Course IV on Exploration for Geothermal Resources, organized by UNU-GTP, KenGen and GDC, at Lake Naivasha, Kenya. P.O. Box 100746. (2009) 1 - 24.
[14] Abdioglu E., "Mineralogy and chemistry of zeolites and associated minerals in Tertiary alkaline volcanics from the Eastern Pontides, NE Turkey", mineralogy Abh 189/1 (2011) 35-47.

[15] Bish D.L., Ming D.W., "Natural Zeolites: occurrence, properties, applications", Mineralogical Society of America, Geochemical Society 45 (2001 )654 p.

[16] Evans JR, H. T., Judith A., Konnert, J. A., Ross M., "The crystal structure of tetranatrolite from Mont Saint-Hilaire, Quebec, and its chemical and structural relationship to paranatrolite and gonnardite", American Mineralogist 85 (2000) 1808-1815.

[17] Coombs D.S., Alberti A., Armbruster T., Artioli G., Colella C., Galli E., Grice J.D., Liebau F., Mandarino J., Minato, H., Nickel, E., Passaglia,.E., Peacor, D.R., Quartieri, S., Rinaldi, R., Ross, M., Sheppard, R.A., Tillmanns E., Vezzalini G., "Recommended nomenclature for zeolite minerals: report of the subcommittee on zeolites of international mineralogical association commission on new minerals and mineral names", The Canadian Mineralogist 35 (1997) 1571-1606.

[18] Pawaiya P., Pawaiya A., Agrawal N., Tomar R., "Synthesis, Characterization of Thomsonite Zeolite for Knoevenagel Condensation", International Journal of Chemical and Physical Sciences 6 (2014) 2319-6602.

[19] Baerlocher Ch., Mc Cusker L.B., Olson D. H., "Atlas of zeolite framework types", Rutgers University, Published on behalf of the Structure Commission of the International Zeolite Association by Amsterdam - London - New York Oxford - Paris - Shannon - Tokyo (2007) 398p.

[20] Stahl, K., Kvick, A. Smith, J.V. "Thomsonite, a neutron diffraction study at $13 \mathrm{~K}$ ". Acta Crystallogr 46 (1990) 1370-1373.

[21] Alberti A., Pongiluppi D., Vezzalnini G., "The crystal chemistry of natrolite, mesolite and scolecite", Neues Jahrb. Mineral Abh 143 (1982) 231-248 
[34] Graham I. T., Pogson R. E., Colchster D. M. Baines A., "Zeolite crystal habits, compositions, and paragenesis; Blackhead Quarry, Dunedin, New Zealand", Mineral Mag 67 (2003) 625-637.

[35] Kristmannsodottir H., Tomasson J., "Zelite zones in geothermal areas in Iceland", In: Sand L.B. and Mumpton F.A. (Eds.) Natural Zeolites. Pergamon, Oxford (1978) 277-284.
[32] Iijima A., Hay R.L., "Analcime composition in tuffs of Green River Formation of Wyoming", American Mineralogist, 53 (1968) 184-200.

[33] Pe-Piper G., "Mode of occurrence, chemical variation and genesis of mordenite and associated zeolites from the Morden area, Nova Scotia, Canada", The Canadian Mineralogist 38 (2000) 1215-1232. 